\title{
Responsabilidad social y relaciones laborales en España
}

\author{
FRANCISCO JAVIER CALVO GALLEGO*
}

\begin{abstract}
SUMARIO: INTRODUCCIÓN.- I. EL PUNTO DE PARTIDA Y EL CONTEXTO DE LA CUESTIÓN: EL MARCO EUROPEO Y SU IMPACTO EN LA DISCUSIÓN ESPAÑOLA SOBRE RSE.- II. LA ACTUACIÓN DE LOS PODERES PÚBLICOS ESPAÑOLES.- III. LA OPINIÓN DE LOS INTERLOCUTORES.- IV. LAS PERSPECTIVAS DE FUTURO: EL ANTEPROYECTO DE LEY DE ECONOMÍA SOSTENIBLE.
\end{abstract}

\section{INTRODUCCIÓN}

Aunque es cierto que la responsabilidad social de las organizaciones es, por su misma esencial y origen, un tema global —como globales son también las preocupaciones y los retos ante los que se enfrenta, en este principio de siglo, la humanidad-, no es menos cierto que, en su desarrollo cronológico, en su evolución material, en la actitud de los agentes económicos y sociales, e incluso en las políticas desarrolladas por parte de cada uno de los distintos poderes públicos implicados, es posible apreciar notables matices y singularidades propias de cada región geográfica o política.

Normalmente, estas diferencias «geográficas» suelen escenificarse recordando las distintas perspectivas - básicamente filantrópicas frente a las de estratégica y gestión - con las que se han aproximado tradicionalmente a este concepto los Estados Unidos y la Unión Europea ${ }^{1}$. Pero no debemos olvidar cómo, al menos a nuestro juicio, estas diferencias son igualmente perceptibles entre los mismos países de la Unión. Y es que basta observar las distintas prácticas empresariales desarrolladas bajo este concepto ${ }^{2}$, las diversas políticas e instrumentos de apoyo público frente a ellas ${ }^{3} \mathrm{o}$, por poner un último ejemplo, su dispar desarrollo

Es profesor titular de la Universidad de Sevilla, en España.

1 En este sentido, suele ser común recordar cómo, mientras en Estados Unidos esta responsabilidad social parece haber estado ligada tradicionalmente a la idea o a la vertiente filantrópica de donación en el ámbito local, en el denominado modelo europeo, fuertemente inspirado por la acción de la Comisión Europea, esta lógica se habría centrado en una forma concreta de actuar social y medioambientalmente sobre el núcleo del negocio, complementada por una clara inversión en la comunidad local y un diálogo estable y sincero con los grupos de interesados. Sobre esta distinción, por lo demás bastante común, véase por todos "Corporate social responsability-What does it mean?», en <http://www.mallenbaker.net/csr/csrfiles/definition.html>. Y ello sin olvidar que, como recuerda M. Gjølberg, hay signos de que este «concepto europeo de la RSE [...] ya estaría ganando en Estados Unidos». En «¿Cuantificando lo incuantificable? Creación de un índice de prácticas de RSE y rendimiento de la RSE en 20 países». Revista de Responsabilidad Social de la Empresa, № 2. En <http://www.fundacionluisvives.org/rse/digital/2/articulos/39078/index.html>.

2 Véase, por ejemplo, SegaL, J.P.; A. SoBCZAK, C.E. TRIOMPhE. Corporate social responsibility and working conditions. European Foundation for the Improvement of Living and Working Conditions.

3 Sobre los distintos modelos de actuación gubernamental en este campo, que irían desde el modelo de «partenariado» propio de los países nórdicos, hasta el modelo ágora propio de los mediterráneos, pasando por los de empresa en la comunidad -típico de los anglosajones- o sostenibilidad y ciudadanía característicos de los países centroeuropeos, véase, LOZANO, J.M.; L. ALBAREDA y T. YSA. «¿Qué pueden hacer los gobiernos para promover la Responsabilidad Social de la Empresa (RSE)?». 
cronológico o la heterogénea relación entre el marco normativo y la Responsabilidad Social Empresarial (RSE) —-sobre todo en lo que se refiere a la obligatoriedad o no de información en materia social o medioambiental - para comprobar cómo estas realidades nacionales distan mucho de ser absolutamente uniformes y homogéneas.

Desde esta perspectiva, las páginas que siguen no pretenden analizar las múltiples cuestiones que la RSE plantea a nivel global, y en especial en el campo laboral ${ }^{4}$, sino de manera bastante más modesta y limitada brindar una breve noticia de la evolución y de las características de este debate en la realidad económica y social española, con especial atención a los aspectos laborales dentro de ella y a la opinión y a las actitudes de los interlocutores sociales.

Para ello analizaremos, en primer lugar, el contexto y el momento en el que surge este debate, para analizar posteriormente el papel de los poderes públicos tanto estatales como autonómicos en su promoción, y concluir abordando, aunque sea brevemente, la posición de los interlocutores sociales y la relación entre la RSE y la negociación colectiva en España.

\section{EL PUNTO DE PARTIDA Y EL CONTEXTO DE LA CUESTIÓN: EL MARCO EUROPEO Y SU IMPACTO EN LA DISCUSIÓN ESPAÑOLA SOBRE RSE}

En este sentido, y al menos a nuestro juicio, los dos primeros rasgos que podrían identificar la evolución de esta idea en España son, de un lado, su carácter temporalmente tardío, sobre todo si lo comparamos con otros países de nuestro entorno cultural, y, del otro, su íntima conexión, la notable influencia que, especialmente en un primer momento, tuvo la actitud de la hoy Unión Europea en esta materia.

\section{I.1. La tardía aparición de la RSE en España: algunos fac- tores que la justifican}

Por lo que se refiere al primero de estos datos, es evidente que en España esta discusión solo comienza con propiedad, o al menos alcanza una cierta relevancia social, en los últimos años de la década de 1990 y, sobre todo, en los primeros años del presente siglo. A diferencia de lo que aconteció en otros muchos países donde la discusión sobre la RSE

CIRIEC-España. Revista de Economía Pública, Social y Corporativa, № 53, 2005. Un elenco de estas políticas en los distintos países de la Unión Europea puede analizarse en el documento de la European Commission, Directorate-General for Employment, Social Affairs and Equal Opportunities, Unit D. 2. Corporate social responsibility national public policies in the European Union. Luxemburgo: Office for Official Publications of the European Communities, 2007.

4 De entre la amplísima doctrina española, nos limitaremos a citar por su actualidad los siguientes libros: FERNÁNDEZ AMOR, J.A. y C. GALA DURÁN (coordinadores). La responsabilidad social empresarial: un nuevo reto para el Derecho. Madrid: Marcial Pons, 2009; TAScón LóPEZ, R. Aspectos jurídicolaborales de la responsabilidad social corporativa. Madrid: CEF, 2008; RODRíGUEZ-PIÑERO ROYO, M. Responsabilidad social corporativa y relaciones laborales en Andalucía. Córdova: Confederación Sindical de Comisiones Obreras de Andalucía, 2008; AUTORES VARIOS. La responsabilidad social empresarial en Europa y las corporaciones transnacionales, número monográfico de Cuadernos de Relaciones Laborales, vol. 27, № 1, 2009. 
se inició a mediados de los sesenta y setenta del siglo pasado ${ }^{5}$, en España el inicio de esta discusión es mucho más tardío y viene a coincidir con el impulso que, desde la Unión Europea, se da a estas cuestiones ${ }^{6}$. De hecho, y como veremos, las primeras actuaciones públicas, las iniciativas parlamentarias o los acuerdos de los interlocutores sociales que de alguna manera abordan esta cuestión se suceden, a un ritmo, eso sí, bastante acelerado, en esta última década?

Son varias, seguramente, las razones que justifican este retraso. La primera de ellas, al menos a nuestro juicio, es la singular situación en la que se encontraba nuestro sistema de relaciones laborales en la década de 1950 o 1960, esto es, en el momento en el que los primeros atisbos de esta forma de gestión empresarial aparecían ya en otros países europeos como Bélgica e Italia. Aunque formalmente corporativista, la concepción de la empresa imperante, bajo la dictadura franquista, era netamente autoritaria. Y si a ello sumamos la situación política de aquel momento, que reprimía cualquier forma de organización social de carácter reivindicativo — que pudiera, por tanto, organizar a los grupos de interesados para favorecer un inexistente debate-, la escasa preocupación medioambiental de un país en buena parte aún en vías de desarrollo, y la escasa internacionalización derivada de una política de aislamiento y autarquía que acaba prácticamente de terminar en la década de los cincuenta, tendremos, al menos a nuestro juicio, las razones que justificaron la ausencia de un debate que, por otra parte, en ningún caso pudo pretenderse sustituido por unas fórmulas de «acción social» - o ayudas diversas muy desarrolladas, eso sí, en aquel modelo de empresa- básicamente paternalistas y destinadas a acallar, en lo posible, la creciente contestación social.

El paso progresivo a un sistema democrático de relaciones laborales sirvió en buena parte para permitir la aparición de estos interlocutores, tanto sociales como sindicales, que pudieran organizar y articular a los distintos grupos de interés. Pero el carácter progresivo de este tránsito,

5 Aunque la cuestión, obviamente, dista de ser clara, suele situarse como fecha inicial de todo este proceso la publicación en 1953 de la obra BOWEN, H. Social responsibilities of the businessman. Nueva York: Harper, 1953. Es cierto que existen estudios anteriores como los de BARNARD, C. The functions of the executive (1938) o el de KREP, T. Measurement of the social performance of business (1940), que suelen mencionarse igualmente en este ámbito. También se suele hacer referencia a las obras de HEALD M. Management's responsibility to society: the growth of an idea (1957), disponible en <http://www.jstor.org/pss/3111413>; y MCGUIRE, J.W. Business and society (1963). Pero existe un cierto consenso doctrinal en atribuir al primero de los antes mencionados el inicio formal del concepto de responsabilidad social. Y de hecho, incluso en algunos países como Japón, suele asociarse el inicio de este proceso con el impacto de la mencionada obra. En este sentido, véase BEOM KIM, Kee. Finding an entry point for the promotion of corporate social responsibility in small and medium-sized enterprises in Japan. Tokio: Japan Institute for Labour Policy and Training, 2005.

6 En este sentido, véase el interesante trabajo de ARAGÓN, J. y F. ROCA. «Los actores de la responsabilidad social empresarial: el caso español». En La responsabilidad social empresarial en Europa. Óp. cit., p. 149.

7 Así lo recordaba el documento aprobado durante la V Sesión del Foro de Expertos del Ministerio de Trabajo, «El desarrollo de la Responsabilidad Social de las Empresas en España». En <http://www. mtin.es/es/empleo/economía-soc/RespoSocEmpresas/docs/INFORME_FOROEXPERTOS_RSE. pdf>, p. 24. Según este: «en España hasta el año 2003 el desarrollo de la RSE era todavía muy incipiente y embrionario [...] el debate público sobre la RSE llegó a España algunos años más tarde que a otros países europeos". 
la escasa aunque creciente preocupación ambiental, la reducida internacionalización de nuestras empresas y, por tanto, de nuestros propios sistemas de gestión — en este sentido, no deja de ser llamativo que la RSE esté especialmente extendida en aquellas comunidades en donde se registra mayor presencia de multinacionales-, el reducido tamaño de la mayor parte de nuestro tejido productivo, el escaso peso de la inversión socialmente responsable, la escasa cultura empresarial existente - al menos en esta materia - y la escasa preocupación tanto de las administraciones públicas como de unos agentes sociales preocupados en aquellos años sobre todo por la grave situación del empleo y por la actualización de un modelo legal y convencional de relaciones laborales en parte heredado del franquismo hicieron, como decimos, que este debate estuviera casi totalmente ausente de la realidad social y empresarial española durante la década de 1980 y la mayor parte de la de $1990^{\circ}$.

Y que además, cuando finalmente surja, lo haga con un gran déficit conceptual e instrumental: esto es, que lo haga sin conocer claramente qué era y qué es la responsabilidad social y, sobre todo, cómo podía y puede aplicarse a la empresa y qué instrumentos pueden utilizarse para incorporarlos al modelo de gestión o a la propia concepción de empresa que supone la RSE9 . Y ello porque, como decimos, a las tradicionales dificultades de un concepto reacio a cualquier definición legal, a las tradicionales dificultades de un concepto articulado con una terminología ciertamente anfibológica, y a las tradicionales dificultades derivadas de un concepto de geometría variables —que, como en la célebre novela de Lawrence Durrell, puede ser vista desde innumerables perspectivas sociales, empresariales, ideológicas o incluso desde ramas del conocimiento, todas ellas ciertas, pero al mismo tiempo incompletas y limitadas-, se unía ahora un retraso de casi cincuenta años.

De ahí que, en gran parte, el impulso y los referentes iniciales de todo este debate se encuentren más allá de nuestras fronteras, en lo que hoy es la Unión Europea y en el conocido Libro Verde de la Comisión Europea, cuya influencia, sobre todo conceptual, ha sido enorme, no solo desde una perspectiva académica, sino también entre los interlocutores sociales y entre los agentes políticos de nuestro país.

Con todo, no quisiéramos dejar de señalar cómo, junto a este impulso conceptual, también se produjo otro, a veces ciertamente minusvalorado, pero a nuestro juicio igualmente trascendente: nuestra incorporación, paulatina y casi generacional — como casi todas las cuestiones realmente

8 ARAGÓn, J. y F. ROCA. «Los actores de la responsabilidad social...». Óp. cit., p. 149, y las obras por ellos mencionadas.

9 De ahí, al menos a nuestro juicio, el éxito de fórmulas «estandarizadas» como el Pacto Mundial o la progresiva pujanza de normas técnicas como la SGE 21:2008 o la SA 8000 en España. Con respecto al primero, la Asociación Española del Pacto Mundial (ASEPAM) se creó el 15 de noviembre de 2004 - como se ve, una fecha ciertamente tardía-, pero, de acuerdo con sus propios datos, en diciembre de 2009 habría un total de 897 firmantes, de los que, eso sí, solo 223 estarían asociados. En relación con la SGE 21:2008 y Forética —que en el 2010 celebrará su décimo aniversario-, puede consultarse su interesante página web: <http://www.foretica.es/es>. 
de calado- a un modelo social europeo en el que cuestiones como la ecología, la sostenibilidad social, económica y medioambiental, o la importancia de los consumidores y de sus elecciones de consumo en una sociedad libre de dominio y asentada cada vez más sobre las Tecnologías de Información (TIC), iban incorporándose poco a poco, pero cada vez más intensamente, a nuestro propio tejido y conciencia social.

\section{I.2. El papel de la Unión Europea en el fomento de la RSE: algunas notas}

En este contexto, se comprenderá fácilmente la necesidad de encuadrar la evolución de la RSE en España dentro de ese apoyo conceptual e instrumental que proporcionó la hoy Unión Europea.

Así, suele ser habitual situar el punto de partida de todo este proceso en el tantas veces citado Libro Verde. Pero no está de más recordar cómo, dejando a un lado antecedentes incluso más remotos ${ }^{10}$, el punto inicial de este proceso comunitario es algo anterior, y puede situarse en la Cumbre Europea de Lisboa del 23 y el 24 de marzo de 2000'11. Durante esta cumbre, que lanzaría la denominada Estrategia de Lisboa, llamada a convertir a Europa en la «economía del conocimiento más competitiva y dinámica del mundo, capaz de un crecimiento económico duradero, acompañado por una mejora cuantitativa y cualitativa del empleo y una mayor cohesión social», el Consejo Europeo hacía «un llamamiento especial al sentido de responsabilidad social de las empresas con respecto a las prácticas idóneas en relación con la formación continua, la organización del trabajo, la igualdad de oportunidades, la integración social y el desarrollo sostenible» ${ }^{12}$. Obsérvese, por tanto, la íntima conexión de este concepto con los aspectos sociales, y específicamente laborales, a los que se unía la inevitable conexión con la Estrategia de Desarrollo Sostenible que poco después daría sus primeros pasos ${ }^{13}$.

10 Sobre estos antecedentes - básicamente el llamamiento de J. Delors a una participación activa de las empresas en la lucha contra la exclusión social-y con una amplia referencia a la evolución de estas cuestiones en el ámbito de la Unión puede consultarse <http://www.csreurope.org/pages/en/ history.html >. Véase, igualmente, lo señalado en la nota al pie 16.

11 En general, sobre los antecedentes y el papel de la UE hasta 2003, es ciertamente destacable por completo el trabajo de Sото, F. Alonso. «Estrategia europea de la responsabilidad social de las empresas". Revista del Ministerio de Trabajo e Inmigración, № 62, 2006, pp. 79 y siguientes.

12 En <http://www.europarl.europa.eu/summits/lis1_es.htm>.

13 Tras algunos antecedentes como el Club de Roma de 1968, la primera Conferencia sobre el Medio Humano de Estocolmo de 1972, o el informe «Brundtland. Our common future», publicado en 1987 -y que, a su vez, era fruto de los trabajos de la Comisión Mundial de Medio Ambiente y Desarrollo de Naciones Unidas, creada durante Asamblea de las Naciones Unidas en 1983-, el Tratado de Ámsterdam convirtió ya en 1997 el desarrollo sostenible en uno de los objetivos de la UE. De esta forma, se conectaba con la Cumbre de la Tierra en Río de Janeiro, en 1992, celebrada al amparo de la ONU y que adoptó la Agenda 21 y la Declaración de Río sobre Medio Ambiente y Desarrollo. En cualquier caso $-\mathrm{y}$ dejando a un lado otros eventos fundamentales como los Objetivos del Milenio, o la Cumbre Mundial sobre Desarrollo Sostenible en Johannesburgo 2002-, la Estrategia Europea para el Desarrollo Sostenible se inició realmente en 2001, en Goteborg, cuando el Consejo Europeo discute «A sustainable Europe for a better world: a European strategy for sustainable development". Tras el lanzamiento de la Estrategia de Lisboa, el apartado medioambiental se sitúa como una tercera línea o estrategia transversal junto con la económica y la de empleo. Las dos estrategias actúan, o debían actuar, complementariamente. Finalmente, tan solo nos gustaría resaltar cómo en julio de 2006, tras una importante Comunicación de la Comisión (2005), se rediseñó

RESPONSABI-

LIDAD SOCIAL Y RELACIONES LABORALES EN ESPAÑA 
Esta conexión con lo social es la que explica de qué manera, poco después, el Consejo Europeo celebrado entre el 7 y el 9 de diciembre de 2000 en Niza - y con el antecedente de la Comunicación de la Comisión del 28 de junio de $2000^{14}$ — aprobara la Agenda Social Europea de Niza, dentro de cuyo apartado II, «Anticiparse a los cambios del entorno de trabajo y sacar partido de los mismos, desarrollando un nuevo equilibrio entre flexibilidad y seguridad», se abordaba nuevamente el tema. En este caso, la agenda partía de «las profundas transformaciones de la economía y del trabajo, relacionadas en particular con el nacimiento de la economía basada en el conocimiento y con la globalización» para, entre las «medidas que se adopten para hacer frente a estas transformaciones» —y que debían «dejar un gran margen de iniciativa a los interlocutores sociales»mencionar la necesidad de «apoyar las iniciativas relativas a la responsabilidad social de las empresas y a la gestión del cambio por medio de una Comunicación de la Comisión» ${ }^{15}$ Además, esta responsabilidad social era igualmente traída a colación — en este caso, con el claro antecedente del Libro Blanco. Crecimiento, competitividad y empleo de $1993^{16}$ — al señalar la necesidad de involucrar a las empresas en la lucha contra la pobreza y la exclusión social mediante el fortalecimiento de su responsabilidad social.

Pues bien, con estos antecedentes $-\mathrm{y}$ con los que le proporcionaban el Consejo Europeo de Estocolmo (23 y 24 de marzo de 2001) ${ }^{17}$ y la Comunicación de la Comisión sobre Desarrollo Sostenible aprobada en el Consejo Europeo de Gotemburgo ${ }^{18}$ - la comisión procedió a publicar —originalmente en francés- el tan mencionado Libro Verde.

la Estrategia Europea para el Desarrollo Sostenible (EDS). El Consejo de Bruselas señaló así que «Un desarrollo sostenible significa que las necesidades de la actual generación deberían satisfacerse sin comprometer la posibilidad de que las futuras generaciones satisfagan sus propias necesidades. Constituye un objetivo general de la Unión Europea que figura en el Tratado, y que rige todas las políticas y actividades de la Unión. Se trata de preservar la capacidad de la Tierra para sustentar la vida en todas sus formas. Se basa en los principios de democracia, igualdad de género, solidaridad, Estado de derecho y respeto de los derechos fundamentales, incluidas la libertad y la igualdad de oportunidades para todos. Su objetivo es la mejora continua de la calidad de vida y el bienestar de los habitantes del planeta y de las futuras generaciones. Para ello, fomenta una economía dinámica con un alto nivel de empleo y educación, de protección de la salud, de cohesión social y territorial y de protección del medio ambiente en un mundo seguro y en paz, respetando la diversidad cultural». Y se recuerda que «el reto principal es cambiar de modo gradual nuestros actuales modelos de consumo y producción no sostenibles, así como el enfoque no integrado para elaborar políticas».

14 Comunicación de la Comisión al Consejo, al Parlamento Europeo, al Comité Económico y Social y al Comité de las Regiones Agenda de Política Social, Bruselas, 28.6.2000 COM (2000), 379 final.

15 Diario Oficial de las Comunidades Europeas, 30 de mayo de 2001 (2001/C 157/02).

16 Como se recordará, en este Libro Blanco de Delors se presentaba una estrategia para desarrollar el empleo y la creación de empresas en Europa que fue aprobada por el Consejo Europeo celebrado en Bruselas durante diciembre de ese año, y en el cual se convocaba a las empresas europeas a participar en la lucha contra la exclusión social.

17 En su epígrafe V, «Modernización del modelo social europeo», conclusión 31, se hacía expresa referencia al concepto, a la práctica y a las perspectivas de futuro: «El Consejo Europeo acoge favorablemente las iniciativas tomadas por el sector empresarial para fomentar la responsabilidad social de las empresas. La Comisión ha anunciado que se propone presentar, en junio de 2001, un Libro Verde [sic] sobre dicha cuestión y fomentar un amplio cambio de impresiones con vistas a apoyar otras iniciativas en dicho ámbito".

18 Comunicación de la Comisión del 15 de mayo de 2001. «Desarrollo sostenible en Europa para un mundo mejor: estrategia de la Unión Europea para un desarrollo sostenible (Propuesta de la Comisión ante el Consejo Europeo de Gotemburgo)» [COM (2001), 264 final, no publicada en el Diario Oficial]. En ella se señalaba cómo «La actuación pública también desempeña un papel fundamental a la hora de crear una mayor sensación de responsabilidad social colectiva y de establecer un marco por el que las empresas deban integrar consideraciones ambientales y sociales en sus actividades [...] 
Fomentar un marco europeo para la responsabilidad social de las empresas ${ }^{19}$, que recibió más de 250 respuestas y supuso todo un hito en el desarrollo y delimitación a nivel europeo de este concepto.

Aunque el Libro Verde contemplaba la relación entre la RSE y otros aspectos como la «elevación de los niveles de desarrollo social, la protección medioambiental y respeto de los derechos humanos», además de «un modo de gobernanza abierto que reconcilia intereses de diversos agentes en un enfoque global de calidad y viabilidad», lo cierto es que, como el mismo documento recordaba, su atención «se centra, principalmente, en las responsabilidades de las empresas en el ámbito social», algo por lo demás lógico si recordamos su conexión con la Estrategia de Lisboa, la Agenda Social y otras experiencias internacionales.

De su amplio contenido - 35 páginas en su versión española — nos interesa destacar algunos aspectos, sobre todo por su influencia en la práctica posterior española. En primer lugar, su definición asentada sobre dos rasgos fundamentales: la voluntariedad o unilateralidad, e, íntimamente conectada con lo anterior, la adicionalidad o el hecho de concretarse en actuaciones que vayan más allá (beyond) del marco legal u obligatorio en el que se desplaza la empresa. Desde esta perspectiva, la comisión identificaría esta RSE como la «integración voluntaria, por parte de las empresas, de las preocupaciones sociales y medioambientales en sus operaciones comerciales y sus relaciones con sus interlocutores», actitud que - frente a algunas posturas neoconservadoras estadounidenses«no se debe considerar sustitutiva de la reglamentación o legislación», pero que se conecta en reiteradas ocasiones con la mayor productividad, competitividad y adaptación al cambio de las propias empresas. Esto es, como un instrumento de soft-law, o incluso mejor, como un compendio de instrumentos de soft-law que pueden y deberían ser utilizados como mecanismos para lograr los fines diseñados en la Estrategia de Lisboa.

El segundo elemento que nos interesa destacar es la articulación de esta RSE en dos grandes vertientes o dimensiones. La dimensión interna de la empresa englobaría las prácticas más cercanas a los aspectos laborales al abarcar las inversiones en capital humano, salud y seguridad, y gestión del cambio ${ }^{20}$. Por el contrario, en su dimensión externa, la comisión destacaba la necesidad de que las empresas colaborasen con la comunidad local, al proporcionar, fundamentalmente, puestos de trabajo, salarios, servicios e ingresos fiscales ya que, en definitiva, las empresas dependen

Debería animarse a las empresas a adoptar un enfoque proactivo en materia de desarrollo sostenible en sus operaciones, tanto dentro como fuera de la Unión Europea».

19 COM (2001), 366 final, de 18.7.2001.

20 En concreto, se mencionaban áreas como «el aprendizaje permanente, la responsabilización de los trabajadores, la mejora de la información en la empresa, un mayor equilibrio entre trabajo, familia y ocio, una mayor diversidad de recursos humanos, la igualdad de retribución y de perspectivas profesionales para las mujeres, la participación en los beneficios o en el accionariado de la empresa y la consideración de la capacidad de inserción profesional y la seguridad en el lugar de trabajo», aspectos a los que se unía igualmente una adecuada gestión del cambio y reestructuraciones socialmente responsables. Finalmente, la comisión también incluía en esta «dimensión» las prácticas respetuosas con el medio ambiente relacionadas con la gestión de los recursos naturales empleados en la producción.

RESPONSABILIDAD SOCIAL Y RELACIONES LABORALES EN ESPAÑA 
de la buena salud, de la estabilidad y de la prosperidad de las comunidades donde operan ${ }^{21}$.

Desde este punto de partida, y sin poder detenernos mucho en la actividad posterior de la Unión en este campo —que, aun cuando provocó un notable interés entre estudiosos e interlocutores, tuvo, sin embargo, al menos a nuestro juicio, un menor impacto en la realidad y discusión española-, tan solo destacaremos cómo en julio de 2002 se publicó una segunda Comunicación de la Comisión denominada «Responsabilidad social de las empresas: una contribución empresarial al desarrollo sostenible ${ }^{22}$. En ella, y tras analizar las más de 250 respuestas al Libro Verde, los retos a los que se enfrentaba la RSE — y que, por cierto, podían trasladarse casi punto por punto a la realidad española ${ }^{23}$-, e incluir en la definición, además de la adicionalidad y voluntariedad, su conexión con el desarrollo sostenible y su íntima relación con la gestión empresarial, propuso una estrategia apoyada sobre seis grandes ideas y focalizada en siete grandes áreas ${ }^{24}$. De esos seis principios, seguramente interesa la reiteración de la naturaleza voluntaria de la RSE, la exigencia de prácticas de responsabilidad social creíbles y transparentes, la potenciación de un enfoque equilibrado y global de la RSE que incluyese los aspectos económicos, sociales y ecológicos, así como los intereses de los consumidores -obsérvese, ya que la primitiva prioridad de los aspectos sociales se va diluyendo dentro de una más amplia orientación de los grupos de interesados, lo que no deja de ser ajeno a la progresiva preocupación por este tema por otras direcciones generales distintas a la de empleo-, y la atención a las necesidades y características de las PYME, unida, finalmente, al apoyo y a la coherencia con los acuerdos internacionales existentes - en especial, las normas fundamentales del trabajo adoptadas por la OIT y las directrices de la OCDE para las empresas multinacionales-.

Posteriormente, en octubre de 2002, y como cumplimiento de la anterior comunicación, se organizó finalmente un Foro de Grupos

21 En ese sentido, la responsabilidad social de las empresas se extendería a una amplia variedad de partes interesadas que incluirían a socios comerciales y proveedores, consumidores, autoridades públicas y ONG defensoras de la comunidad local y del medio ambiente.

22 COM (2002), 347 final, de 2.7.2002.

23 La comunicación mencionaba «la falta de información sobre la relación que existe entre la responsabilidad social y los resultados económicos de las empresas ('el argumento comercial'); la ausencia de consenso entre las distintas partes interesadas en torno a una definición adecuada de responsabilidad social, que tenga en cuenta su dimensión global, en particular la diversidad de los marcos políticos nacionales; la escasa educación y formación sobre el papel de la RSE, en particular en las escuelas de comercio y de gestión empresarial; la insuficiente sensibilización de las PYME y sus recursos limitados; la falta de transparencia, que se deriva de la inexistencia de instrumentos ampliamente reconocidos para diseñar, administrar y divulgar las políticas en materia de responsabilidad social; el escaso reconocimiento y apoyo de los consumidores e inversores con respecto a los comportamientos socialmente responsables de las empresas» $y$, finalmente, «la falta de coherencia de las políticas públicas".

24 Estas eran (1) incrementar el conocimiento sobre el impacto positivo de la RSE en las empresas y la sociedad, tanto en Europa como en el extranjero, en especial en los países en desarrollo, con lo que se continuaba con el enfoque promocional y voluntario antes señalado; (2) fomentar el intercambio de experiencias y de buenas prácticas sobre RSE entre las empresas; (3) promocionar la formación y cualificaciones en RSE entre los directivos; (4) incentivar la RSE entre las PYMES; (4) facilitar las convergencia y la transparencia de las prácticas y herramientas de RSE; (5) lanzar un foro multistakeholder de ámbito europeo; y (6) integrar la RSE entre las políticas comunitarias. 
Interesados ${ }^{25}$, cuyo informe final ${ }^{26}$ se dio a conocer en julio de 2004 . En él, además de interesantes puntualizaciones sobre el propio concepto de $\mathrm{RSE}^{27}$, se reafirmó la importancia de diversos instrumentos y estándares internacionales ${ }^{28}$, se analizaron los obstáculos y los elementos críticos que promocionarían su desarrollo y se realizaron recomendaciones que destacaban, por ejemplo, la necesidad de aumentar la preocupación y el conocimiento sobre la RSE, la importancia de recabar y diseminar información sobre ella, la trascendencia del desarrollo de las capacidades y de las competencias sobre RSE - por ejemplo, incluyendo la RSE en la educación y los currículos-, al mismo tiempo que se aseguraba un ambiente favorecedor de la RSE y se promocionaba el diálogo con los grupos de interés.

Sin entrar aquí en otras actuaciones, como las diversas jornadas y reuniones internacionales sobre este tema ${ }^{29}$, la actividad del Grupo de Alto Nivel sobre $\mathrm{RSC}^{30}$ o las Resoluciones del Consejo sobre esta materia $^{31}$, para concluir este apartado baste con indicar, en primer lugar, que en 2006 la comisión volvió a publicar una tercera comunicación bajo el

25 Más información disponible en <http://circa.europa.eu/irc/empl/csr_eu_multi_stakeholder_forum/info/ data/en/csr\%20ems\%20forum.htm>.

26 Disponible en <http://circa.europa.eu/irc/empl/csr_eu_multi_stakeholder_forum/info/data/en/ CSR\%20Forum\%20final\%20report.pdf>.

27 Se insistió, por ejemplo, en el carácter voluntario, adicional y no sustitutivo de la regulación; en el carácter esencial de la gestión en el núcleo de las actividades empresariales, como instrumento que contribuyese a la sostenibilidad futura de la empresa; en el valor añadido que supone el diálogo con los grupos de interés; en su carácter complementario a otras aproximaciones para asegurar un adecuado comportamiento social y medioambiental; en su carácter de procesos continuo de aprendizaje para la empresa y los grupos de interés; en la importancia de la comunicación y transparencia, así como en su desarrollo dentro la cadena de suministros de la empresa.

28 Básicamente, la tantas veces mencionada Declaración Tripartita de la OIT sobre empresas multinacionales, las directrices para estas mismas multinacionales de la OCDE y el Global Compact, a los que se unen ahora otras Declaraciones de Derechos (Declaración de Derechos Humanos, Convenio Europeo de Derechos Humanos y Libertades Fundamentales, Carta Social Europea...) y varias declaraciones sobre sostenibilidad, medio ambiente o derechos de los consumidores como muestra de su progresiva importancia (Río, Johannesburgo...).

29 Por mencionar solo algunas, recuérdese la audiencia Responsabilidad Social de las Empresas: ¿Existe un Planteamiento Europeo?, organizada por su Comisión de Empleo y Asuntos Sociales el 5 de octubre de 2006, o la más reciente CSR Multistakeholder Forum, desarrollada en Bruselas el 10 de febrero de 2009.

30 EI HLG-CSR de la Comisión Europea (Grupo de Alto Nivel en RSE) se reúne periódicamente en Bruselas para poner en común las políticas de fomento de RSE en la UE. Sobre la última de las reuniones de la que tenemos noticias (Bruselas, 22 de abril de 2009), véase <http://www.mtas.es/es/ empleo/economia-soc/RespoSocEmpresas/docs/NOTA_REUNION_GRUPO_ALTO_NIVEL.pdf>.

31 En este sentido, no puede obviarse la importante Resolución del Consejo del 6 de febrero de 2003, relativa a la responsabilidad social de las empresas [DOCE 18.2.2003, (2003/C 39/02)], precedida, entre otras, por la Resolución del Consejo sobre CSR del 2 y el 3 de diciembre de 2003. También resultan de interés las Conclusiones de la Presidencia, del Consejo de Bruselas, del 20 y el 21 de marzo de 2003 (en <http://www.consilium.europa.eu/ueDocs/cms_Data/docs/pressData/es/ec/75142. pdf $>$ ), de acuerdo con las cuales se instaba a «fomentar la responsabilidad social y medioambiental de las empresas tanto a nivel de la UE como a nivel internacional, así como los medios para promover el comercio justo y sostenible, especialmente mediante el desarrollo de incentivos al comercio de bienes producidos de forma sostenible y fomentando créditos a la exportación coherentes con el desarrollo sostenible»; o las Conclusiones de la Cumbre Europea de Bruselas de los días 22 y 23 de marzo de 2005, dentro de cuyo epígrafe titulado «Un espacio atractivo para invertir y trabajar», conclusión 20, se hace referencia a que las empresas «deben desarrollar su responsabilidad social». En un sentido similar, véase la Comunicación al Consejo Europeo de Primavera, titulada «Trabajando juntos por el crecimiento y el empleo. Relanzamiento de la estrategia de Lisboa» [COM (2005) 24], de acuerdo con la cual la RSE «puede [...] desempeñar una función clave a la hora de contribuir al desarrollo sostenible y reforzar al mismo tiempo el potencial innovador y la competitividad de Europa». 
título «Poner en práctica la asociación para el crecimiento y el empleo: hacer de Europa un polo de excelencia de la responsabilidad social de las empresas» ${ }^{32}$. Esta lanzaba una Alianza Europea, abierta a todas las empresas, para promocionar la RSE, y destacaba que no se trataría de un contrato o instrumento legal, sino, sobre todo, de un medio de movilizar los recursos y las capacidades de las empresas europeas en torno a estas políticas y prácticas.

Además, y en segundo lugar, parece necesario resaltar que este interés por la RSE no ha quedado limitado a la comisión y al consejo, aunque seguramente han sido estas dos las instituciones cuyos actos han tenido mayor impacto en nuestro país. Otros órganos como el Parlamento ${ }^{33} \mathrm{o}$ el Consejo Económico y Social ${ }^{34}$ también han participado activamente en este debate.

Y todo ello sin olvidar, en tercer lugar, que la apuesta clara por la RSE como factor de competitividad parece mantenerse en los más recientes documentos, como demuestra la Agenda Social 2006-2010 35 o el Informe de Competitividad de Europa de 2008 36

\section{II.LA ACTUACIÓN DE LOS PODERES PÚBLICOS ESPAÑOLES}

\section{II.1. La actuación de los poderes públicos a nivel estatal}

En este contexto, y frente a otros países como Dinamarca - que ya en 1994 realizaba campañas públicas sobre esta materia ${ }^{37}$ - o el Reino Unido — que ya en marzo de 2000 creó un órgano administrativo

$32 \operatorname{COM}(2006), 136$ final.

33 En especial, quizás cupiera destacar la Resolución del Parlamento Europeo del 13 de marzo de 2007: P6_TA (2007) 0062

34 Por mencionar solo un acto con un amplio impacto en nuestro país, véase el Dictamen del Comité Económico y Social Europeo, «Instrumentos de información y evaluación de la responsabilidad social de las empresas en una economía globalizada» (2005/C 286/04), del 8 de junio de 2005.

35 Comunicación de la Comisión. Agenda de Política Social [COM (2005), 33 final, no publicada en el Diario Oficial]. De acuerdo con este documento, "La Comisión proseguirá fomentando la responsabilidad social de las empresas. Para potenciar la eficacia y la credibilidad de estas prácticas, la Comisión, en cooperación con los Estados miembros y los protagonistas, presentará iniciativas a fin de mejorar más aún el desarrollo y la transparencia de la responsabilidad social de las empresas».

36 Bruselas, 28.11.2008 COM (2008), 774 final. De acuerdo con esta comunicación, «el impacto positivo de la RSE en la competitividad se pone especialmente de manifiesto en el caso de los recursos humanos, la gestión del riesgo y la reputación, y la innovación [...] Parece haber una relación positiva importante entre la RSE y la competitividad a través de la gestión de los recursos humanos, aun cuando en el caso de algunas empresas los costes adicionales que implica la RSE puedan ser, al principio, superiores a los beneficios que reporta. La RSE es un componente esencial para la gestión del riesgo y la reputación de muchas empresas cuya importancia está en aumento por el escrutinio público cada vez mayor al que están expuestas las empresas. Tratar asuntos de la RSE como la transparencia, los derechos humanos y los requisitos de la cadena de suministro desde una perspectiva de gestión del riesgo ha llevado algunas empresas a descubrir otras repercusiones positivas de la RSE. Algunos aspectos de la RSE, como la creación de puestos de trabajo con condiciones favorables para los trabajadores, puede mejorar la capacidad innovadora de las empresas. La relación positiva entre la RSE y la innovación se refuerza por el hecho de que la innovación reviste progresivamente un carácter de colaboración, y por la tendencia hacia la creación de nuevos valores empresariales a partir de innovaciones dirigidas a abordar los problemas de las sociedades [...]».

37 Como es bien sabido, en este país el Ministerio de Asuntos Sociales lanzó en 1994 la campaña «Nuestra preocupación común: la responsabilidad social del sector empresarial», y fundó en 1998 el Copenhaguen Centre, un auténtico referente en estos aspectos. 
específico competente en el ámbito de la responsabilidad social de las empresas (Minister for Corporate Social Responsibility) ${ }^{38}$ —, en España la actuación de los poderes públicos resultó ser bastante más tardía.

\section{II.1.1. La proposición no de ley del Grupo Socialista de 2002}

Dejando a un lado la preocupación por el buen gobierno corporativo de las empresas ${ }^{39}$ - tema este cuya inclusión o no en el ámbito de la responsabilidad social ha sido siempre objeto de discusión en nuestro país-, lo cierto es que la primera actuación de cierto calado a nivel estatal — si bien precedida de alguna proposición no de ley ${ }^{40}$ — se produjo a principios de esta década, con la presentación en el Congreso de los Diputados de una Proposición de Ley sobre Responsabilidad Social de las Empresas por parte del Grupo Parlamentario Socialista ${ }^{41}$. La mencionada proposición, fuertemente influida por el Libro Verde y por la actuación comunitaria en esta materia, pretendía establecer un completo marco normativo sobre el cual estructurar la RSE: un marco en el que primaban, salvo ciertas obligaciones de transparencias para determinadas grandes empresas, la voluntariedad (artículo 1) y en el que también eran básicos —al menos en aquel momento- los aspectos laborales, aunque se incrementase ya el peso de los aspectos medioambientales.

Baste en este sentido señalar cómo la proposición, tras definir la RSE como la «asunción voluntaria de buenas prácticas de gestión integrada de la empresa en todas sus relaciones, respecto de los valores éticos

38 Además de un grupo interministerial para mejorar la coordinación de las actividades de promoción de la responsabilidad social de las empresas.

39 Se trata básicamente del Informe Olivencia o Documento de la Comisión Especial para el Estudio de un Código Ético de los Consejos de Administración de las Sociedades: el Gobierno de las Sociedades Cotizadas (Madrid, 26 de febrero de 1998), surgido del acuerdo del Consejo de Ministros de 28 de febrero de 1997, por el que se creó una Comisión Especial para el Estudio de un Código Ético de los Consejos de Administración de las Sociedades, sobre el que puede consultarse en <http://www. ciudadessostenibles.es/modules/rsc/face/pdf/informe_olivencia.pdf?PHPSESSID=7dfd13bf499c84a 8e50e8f70d2358892>; y del Informe Aldama o Informe de la Comisión Especial para el Fomento de la Transparencia y Seguridad en los Mercados y en las Sociedades Cotizadas, del 8 de enero de 2003, cuyo texto puede encontrarse en <http://www.nebrija.com/nebrija-santander-responsabilidadsocial/documentos/Informe_Aldama.pdf>. Finalmente, debe hacerse mención al Código Conthe o Código Unificado de Buen Gobierno Corporativo para las Sociedades Cotizadas Españolas, cuyo texto definitivo vio la luz el 19 de mayo de 2006 tras ser sometido a un período de información pública que se inició el 18 de enero de 2006, y tras las diecinueve reuniones del grupo especial de trabajo constituido el 16 de septiembre de 2005 para asesorar a la Comisión Nacional del Mercado de Valores en la armonización y actualización de las recomendaciones de los Informes Olivencia y Aldama.

40 Por ejemplo, la proposición no de ley sobre medidas de impulso de la responsabilidad social corporativa (RSC) para su debate en la Comisión de Economía y Hacienda, presentada por el diputado del Grupo Parlamentario Socialista, Juan Manuel Eguiagaray Ucelay, el 14 de febrero de 2002. Esta proposición no de ley planteaba una llamada «a que los poderes públicos, con sus acciones, promuevan la generalización de estas prácticas, incentiven su adopción por las empresas y contribuyan a la valoración por el público de los comportamientos socialmente responsables debidamente acreditados.» Para ello, se proponía la elaboración de informes de situación y la creación de incentivos económicos y de reconocimiento social que favorecieran la adopción de políticas de responsabilidad social por parte de las empresas. Sobre este tema, véase Fundación Ecología y Desarrollo. Responsabilidad social corporativa y administraciones públicas. Iniciativas en España. Zaragoza: abril de 2003.

41 Boletín Oficial de las Cortes Generales (BOCG), Congreso de los Diputados, VII Legislatura, Serie B: Proposiciones de Ley, 10 de mayo de 2002, № 235-1. 
no exclusivamente financieros o económicos ${ }^{42}$, definía los «elementos determinantes de la responsabilidad social de las empresas», mediante la evaluación «de conformidad a las buenas prácticas» previstas en el o los códigos de conducta ${ }^{43}$, u obsérvese en el convenio colectivo de 35 indicadores divididos en cinco apartados. Pues bien, de estos 35 indicadores, al menos trece hacían referencia a los apartados específicos relativos a recursos humanos y seguridad, y salud laboral, mientras que los aspectos medioambientales se articulaban en siete indicadores y solo se mencionaban cuatro en relación con la vinculación con el entorno local y los proveedores y uno en relación con el co-desarrollo. Si a ello unimos el importante papel otorgado a la consulta con la representación de los trabajadores, obtendremos las razones por las que, como hemos comentado, este proyecto — que también abordaba el balance social, la auditoría, la certificación o la acreditación de las entidades de normalización, certificación y auditoría, o las inversiones socialmente responsables en fondos de pensiones - mostraba, como decíamos, una clara impronta o sesgo laboral, ligado seguramente a la importancia de este tema en el Libro Verde.

En cualquier caso, y a pesar de lo meritorio del proyecto, lo cierto es que seguramente fue un texto en exceso adelantado a su tiempo y que, quizás por ello, no pudo prosperar ${ }^{44}$. Y de ahí también que los siguientes pasos a nivel estatal fueran mucho más cautos y estuvieran centrados en una labor, quizás previa y necesaria, de análisis e investigación del concepto e instrumentos de la RSE.

\section{II.1.2. La subcomisión del congreso: el denominado Libro Blanco}

La necesidad de constituir una subcomisión para el estudio de la responsabilidad social ya fue planteada en la VII Legislatura por el Grupo Mixto ${ }^{45}$, si bien no fue hasta 2005, esto es, en la siguiente legislatura, cuando se constituyó, en el seno de la Comisión de Trabajo y Asuntos Sociales, una subcomisión específica para potenciar y promover la responsabilidad social de las empresas a solicitud del Grupo Parlamentario Socialista ${ }^{46}$.

42 La influencia del Libro Verde se hacía aun más clara cuando, con posterioridad, se señala que comprendía «los aspectos relacionados con la mejora de las condiciones de trabajo, formación y empleabilidad [sic] de los trabajadores, igualdad de oportunidades, el desarrollo sostenible por la aplicación de criterios ecológicos a la adquisición de materias primas, productos intermedios, a las inversiones, a los sistemas de producción y a los productos propios, así como respecto del respeto de los derechos humanos de sus proveedores, contratistas y concesionarios».

43 Definido a su vez como «la declaración formal de una empresa de someterse a una autorregulación vinculante y vinculada al repertorio de las buenas prácticas de responsabilidad social. La exigencia de esas buenas prácticas a proveedores, contratistas y concesionarios para favorecer el desarrollo sostenible y la erradicación de las formas de explotación de la mano de obra infantil y el trabajo forzado".

44 Las razones de la oposición de los entonces mayoritarios grupos parlamentario Popular y Catalán Convergencia i Unió pueden encontrarse en el Diario de Sesiones Congreso de los Diputados, № 298, del 25 de noviembre de 2003.

45 Solicitud de Creación de una Subcomisión para el Estudio de la Responsabilidad Social de la Empresa (158/000057), presentada el 17 de diciembre de 2002 y calificada el 14 de enero de 2003. El resultado de su tramitación fue su decaimiento.

46 BOCG. Congreso de los Diputados № D-24 del 28 de mayo de 2004; DS. Congreso de los Diputados № 58 del 14 de diciembre de 2004, p. 2750. 
Tras una ardua labor, en la que comparecieron, durante poco más de un año, más de cincuenta personas, representantes de múltiples organizaciones públicas y privadas, estatales y autonómicas, la subcomisión concluyó con un auténtico Libro Blanco ${ }^{47}$ sobre responsabilidad social. El texto se encuentra dividido en tres partes, de las cuales, sin duda, la más interesante es la de conclusiones ${ }^{48}$, y, dentro de estas, la parte dedicada a recomendaciones, dividida, a su vez, en cuatro grandes apartados en función del sujeto al que se destinan. De esta forma, el Libro Blanco recoge diecinueve propuestas dirigidas a las empresas y a las asociaciones empresariales, a las que se unen las treinta recomendaciones dirigidas a todas las administraciones públicas estatales, autonómicas y locales ${ }^{49}$, dos recomendaciones a consumidores e inversores y, por último, siete que se dirigen a otros actores, entre los que se incluyen a las $\mathrm{ONG}$, los medios de comunicación y otros agentes.

Como fácilmente se comprenderá, resulta imposible intentar siquiera resumir aquí las 118 páginas de las que se compone el mencionado informe. Baste señalar que, tras asumir la definición del Grupo de Expertos del Ministerio de Trabajo — sobre la que volveremos inmediatamente-, y que complementaría la recogida en el Libro Verde, la subcomisión resaltaba que la «RSE constituye fundamentalmente un proceso, no un estadio final concreto y predeterminado. Es un proceso de escucha activa de las demandas explícitas e implícitas de los diversos grupos de interés, en una interacción continua entre ellos»; se trata de un proceso en el que se destaca la voluntariedad, sin que pueda concebirse como un nuevo plus de exigencias legales y sin que pueda considerarse una moda o una cuestión de gestión empresarial más o menos coyuntural.

En relación con las recomendaciones a las empresas ${ }^{50}$, quizás cabría destacar la petición de que estas adoptasen medidas de autorregulación empresarial sectorial, al mismo tiempo que se destacaba la importancia de promover acciones de concienciación, de sensibilización, de formación y de intercambio de buenas prácticas entre las empresas. Se proponía igualmente la elaboración y difusión de memorias de sostenibilidad, preferentemente de acuerdo con los estándares, mediante lo cual se intensificaría la transparencia y el buen gobierno de las empresas y se impulsaría la elaboración de una triple memoria para las empresas cotizadas. Además, y en relación con la RSE interna, se propugnaba una tendencia a la excelencia en las relaciones laborales y a la calidad en el empleo ${ }^{51}$. Finalmente, la subcomisión propuso también, entre las

47 Así lo calificaba expresamente el diputado R. Jáuregui, auténtico inspirador de la propuesta en su intervención final durante el debate y aprobación del Informe de Conclusiones en la Comisión de Trabajo y Asuntos Sociales (DS. Congreso de los Diputados № 624 del 27 de junio de 2006).

48 BOCG. Congreso de los Diputados № D-424 del 4 de agosto de 2006.

49 Véase, no obstante, el voto particular del Grupo Nacionalista Vasco en relación con estos aspectos (BOCG. Congreso de los Diputados № D-423 del 31 de julio de 2006).

50 Seguimos aquí básicamente su resumen, expuesto por R. Jáuregui en su intervención citada en la nota anterior.

51 De hecho, la subcomisión destacó la importancia de determinados aspectos para configurar la calidad laboral de las empresas, fundamentalmente en lo que se refiere a la integración de la discapacidad, la 
recomendaciones a las empresas, la incorporación a los estatutos de sus compromisos con sus grupos de interés, así como la promoción de las actividades de acción social y la progresiva incorporación de la cultura de la RSE a la larga cadena de proveedores ${ }^{52}$, con el objetivo de retomar los compromisos internacionales en materia de RSE, especialmente en relación con América Latina.

En el capítulo de las recomendaciones a las administraciones públicas, quizás destaque la llamada al impulso de la inversión socialmente responsable — sobre todo por la escasa experiencia española en esta materia- con posibles reducciones fiscales para dichas inversiones, así como la petición de un mejor tratamiento del empleo de las personas con discapacidad o la posibilidad de incluir, en los pliegos públicos de compras y contrataciones, aspectos en los que primase la RSE — tema este sobre el que volveremos más tarde-. También se postulaba, entre otras cuestiones, el fortalecimiento del punto nacional de contacto de la OCDE en nuestro país ${ }^{53}$, la creación de una estructura gubernamental de coordinación de todas las acciones relacionadas con la RSE o, como ocurrió finalmente, la creación de un consejo que facilitase el diálogo multistakeholders por parte del Gobierno. Y todo ello sin olvidar que, en relación con las propias administraciones públicas, el informe recomendaba promover la responsabilidad social también en su gestión, al mismo tiempo que planteaba toda una serie de instrumentos para la expansión de la RSE ${ }^{54}$. Este apartado concluía con una serie de recomendaciones en el capítulo del fortalecimiento a los movimientos de la sociedad civil, así llamados, relacionados con la RSE, fundamentalmente ONG, asociaciones de consumidores, etcétera.

\section{II.1.3. La labor del Grupo de Expertos del Ministerio de Trabajo}

Por otra parte, y al igual que ocurrió con la labor en el congreso, la necesidad de crear un grupo de trabajo en el seno del Ministerio de Trabajo ya fue resaltada en la VII Legislatura cuando el Grupo Popular, entonces en el Gobierno, planteó una proposición por la que se le instaba a crear

protección de la salud y la reducción de la siniestralidad, la formación de los empleados, el fomento de la contratación indefinida, la negociación colectiva en general, y la igualdad hombre-mujer, así como la promoción de la conciliación de la vida laboral y personal.

52 La subcomisión partía, en realidad, de la idea de que la implantación de la RSE en las pequeñas y medianas empresa sería en buena parte consecuencia de que las grandes lo incorporasen como exigencia a sus proveedores.

53 En España, es la Secretaría General de Comercio Exterior el organismo público designado para la promoción, la divulgación y el efectivo cumplimiento de la puesta en práctica de la Líneas Directrices de la OCDE para el Buen Gobierno de las Empresas Multinacionales. Ha sido tradicional destacar su escasa actividad y peso en todo este debate. Más información en <http://www.comercio.mityc.es/ comercio/bienvenido/Inversiones+Exteriores/Punto+Nacional+de+Contacto+de+las+Lineas+Directri ces/pagEspnc.htm>.

54 Como son las herramientas de gestión, los premios y los reconocimientos a las empresas más destacadas en esta materia, la difusión de las buenas prácticas empresariales y, en general, la concreción de las ayudas públicas, sobre todo en la política exterior, créditos FAD, intervenciones CESCE, ICEX, COFIDES, etcétera; a las empresas internacionales relacionadas con sus políticas de RSE. Además, claro está, de impulsar también la creación de normas internacionales en materia de RSE o la elaboración de guías que sirviesen en todo el mundo para favorecer el establecimiento de estas políticas. 
una Comisión Técnica de Expertos, con el fin de elaborar un informe sobre la RSE ${ }^{55}$.

Tras el cambio de gobierno, esta comisión se mantuvo, si bien alterando su composición ${ }^{56}$. Y, finalmente, el denominado Foro de Expertos sobre RSE fue «constituido» en marzo de 2005 con la participación de representantes de varios ministerios y de expertos provenientes de grupos empresariales, organizaciones de la sociedad civil y de la universidad ${ }^{57}$. Tras varias sesiones, su labor concluyó el 12 de julio de 2007 con la elaboración del último documento («Las políticas públicas de fomento y desarrollo de la RSE en España) que, unido a los tres anteriores, dio como resultado un informe con conclusiones de enorme calidad e impacto.

Con la aprobación de ambos documentos —el Informe de la Subcomisión y el del Foro de Expertos, al que podríamos sumar el surgido del diálogo social y sobre el que más tarde volveremos-, podríamos decir que la RSE en España asumió su mayoría de edad y se dotó de un bagaje conceptual y científico propio, aunque sin poder olvidar nunca su origen, inevitablemente ligado al Libro Verde de la comisión y a una experiencia europea en la que ya se integraría sin problemas ni complejos.

Nuevamente, resulta imposible intentar siquiera resumir el contenido de estos «informes». Por ello, y como simple noticia, nos limitaremos a destacar cómo, en primer lugar, y tras resaltar la conexión entre RSE y sostenibilidad, así como los principales instrumentos internacionales en la materia, el foro optará por una definición clara y precisa, asumida como ya hemos visto- incluso por la subcomisión del congreso. Y así, de acuerdo con el primer documento del foro, la RSE sería:

[...] además del cumplimiento estricto de las obligaciones legales vigentes, la integración voluntaria en su gobierno y gestión, en su estrategia, políticas y procedimientos, de las preocupaciones sociales, laborales, medio ambientales y de respeto a los derechos humanos que surgen de la relación y el diálogo transparentes con sus grupos de interés, responsabilizándose así de las consecuencias y los impactos que se derivan de sus acciones... es decir, a una gestión de la empresa que respeta a todos sus grupos de interés y supone un planteamiento de tipo estratégico que

55 Proposición no de ley aprobada el día 17 de febrero de 2003 sobre responsabilidad social corporativa. BOCG. Congreso de los Diputados № D-455 del 13 de diciembre de 2002. Se pretendía entonces la creación de «una Comisión Técnica de Expertos» cuya finalidad fuese «elaborar un informe sobre la responsabilidad social de la empresa, que permita evaluar y garantizar la eficacia y oportunidad de los elementos que la integran». Específicamente, el informe debía «versar sobre los instrumentos adecuados para favorecer la adopción de las mejores prácticas, en particular, a través de la difusión voluntaria de información, posibilidad de crear un organismo certificador o evaluador de la calidad social, implementación de una futura etiqueta social, realización de auditorias e informes sociales, cualesquiera otros aspectos que puedan integrar el concepto de responsabilidad social de la empresa, siempre que no pertenezca al ámbito de la política económica general».

56 Véase la contestación del Gobierno a la pregunta del diputado Campuzano i Canadés, en BOCG. Congreso de los Diputados № D-42 del 24 de junio de 2004, p. 55.

57 La composición del mencionado foro puede consultarse en <http://www.mtin.es/es/empleo/economiasoc/RespoSocEmpresas/docs/ComposicionForoExpertos.htm>.

RESPONSABILIDAD SOCIAL Y RELACIONES LABORALES EN ESPAÑA 
debe formar parte de la gestión cotidiana de la toma de decisiones y de las operaciones de toda la organización.

De ahí que, con la clara influencia del Libro Verde, distinga también entre ámbito interno ${ }^{58}$ y externo, al mismo tiempo que resalta su extensión a todas las operaciones internas y externas, y a toda la cadena de subcontratación de cualquier entidad pública o privada, con o sin ánimo de lucro.

En el segundo documento, fruto de la IV Sesión, se abordó en profundidad el informe de RSE como motor de la responsabilidad social; se entendió por este Informe «la parte más visible y sistematizada de un sistema de información en RSE [...] un documento que se hace público y que, a través de indicadores cualitativos y cuantitativos, muestra el resultado e impacto económico, social y medioambiental de la actividad de la organización que lo realiza en un período de tiempo determinado». Este informe - se continúa- «debe contener datos cuantificables, contrastables y verificables, y se deben expresar de forma objetiva e imparcial para facilitar de esta manera a las diversas partes interesadas una opinión más fundamentada sobre los contenidos de la información publicada». Desde esta perspectiva, el foro instó a los poderes públicos a:

[poner] en marcha una política pública de promoción del Informe de RSE que tenga en consideración los siguientes aspectos: apoyo técnico a las empresas; catálogo de herramientas de información; buenas prácticas de información; perfil de empresas e instituciones incluidas en la política de promoción; temas e indicadores de medida susceptibles de ser incluidos en el Informe de RSE; verificadores y el rol de su labor de verificación; publicidad y transparencia del Informe de RSE.

Todo ello tras considerar que los instrumentos internacionales más utilizados pueden considerarse guías adecuadas para establecer el marco general del contenido de los informes de RSE ${ }^{59}$. En última instancia, como marco de referencia para la elaboración de estos informes, se utilizaría el

58 De acuerdo con este documento, «en su ámbito interno (la RSE) se refiere por un lado al respeto al medio ambiente en la actividad de la empresa, en la medida en que la calidad y la conservación de éste, como marco en el que se desarrolla la vida y como fuente de recursos, preocupa a los grupos de interés. Y se refiere por otro lado a los derechos de sus trabajadores a la libre negociación colectiva, a la igualdad de oportunidades entre hombres y mujeres, a la no discriminación por razón de edad, origen racial o étnico, religión o discapacidad, a la salud y seguridad laboral, y a la conciliación de la vida personal o familiar y laboral. En el ámbito externo se refiere al respeto riguroso a los derechos de los clientes y consumidores que compran sus productos y servicios o de sus proveedores, al respeto a los Derechos Humanos y a la no connivencia con la corrupción o con el soborno, y la acción cultural, medioambiental o social de las empresas, entendida ésta última como la asignación de recursos empresariales a proyectos relacionados con personas desfavorecidas en las comunidades donde opera la empresa».

59 Expresamente se mencionan los más conocidos, esto es, y en palabras del propio foro, entre otras, «las normas y acuerdos internacionales por su carácter universal y representatividad», tales como el «Pacto Mundial de Naciones Unidas sobre derechos humanos, relaciones laborales, medioambiente y lucha contra la corrupción; la declaración tripartita de principios sobre las empresas multinacionales y la política social de la Organización Internacional del Trabajo (OIT); las líneas directrices de la Organización para la Cooperación y el Desarrollo Económico (OCDE) para las empresas multinacionales; y las directrices de Global Reporting Iniciative (GRI)» 
Dictamen del Comité Económico y Social Europeo: «Instrumentos de información y evaluación de la responsabilidad social de las empresas en una economía globalizada ${ }^{60}$.

Finalmente, el último de los documentos de este foro abordaba el papel de las políticas públicas de fomento y de desarrollo de la RSE en España, y se profundizaba en ideas ya elaboradas en su primer documento ${ }^{61}$. Así, se apostaba, en primer lugar, por una mayor información y sensibilización de los actores y de los ciudadanos sobre la RSE, bien a través de campañas informativas o a través del uso de las nuevas TIC, del mismo modo que, en segundo lugar, se postulaba el consumo responsable para promover - entre otras medidas - la utilización del etiquetado como herramienta distintiva.

En tercer lugar, se apoyaba la participación, el conocimiento, la implicación y la corresponsabilidad, mediante, entre otras medidas, el fomento de la investigación sobre RSE y el desarrollo sostenible, su inclusión en la educación universitaria y no universitaria, el fomento de estas capacidades en la sociedad civil y en los directivos de las empresas, así como mediante el apoyo al conocimiento e intercambio de buenas prácticas.

En cuarto lugar, se instaba igualmente a que las administraciones públicas integrasen «los principios de responsabilidad en sus propios sistemas de gestión y en las relaciones con terceros», así como el impulso «dentro del Estado, en todas sus actividades económicas, empresas públicas y organismos públicos», de «las mismas pautas de conducta responsable». En este sentido, en el caso de aprovisionamientos públicos, implicaría la exigencia de determinados requisitos en términos de RSE en la ejecución de los contratos con la administración. Y todo ello sin olvidar las menciones a la aprobación de códigos de conducta para los empleados públicos, el fomento de la Inversión Socialmente Responsable (ISR), la inclusión de la RSE «como criterio informativo en la ejecución de las ayudas públicas concedidas a los distintos sectores empresariales» y «dotar de recursos suficientes (financieros y técnicos) al Punto Nacional de Contacto (PNC)».

60 Véase la nota al pie 33.

61 En aquel primer documento se señalaba que «Los poderes públicos pueden y deben establecer políticas públicas como las siguientes: 1) Unas políticas de promoción e incentivos de la RSE, aplicables no sólo a las grandes empresas, sino también a las PYMEs [sic]. 2) Se deben regular y universalizar los aspectos cruciales que dan credibilidad y rigor a la RSE: el reporte de las empresas a las partes interesadas y a la sociedad en general y la verificación de dicho reporte. 3) Una tarea de fomento, es decir, de educación y formación, información y apoyo técnico para el desarrollo de la RSE entre los diversos agentes de la sociedad civil, en toda la sociedad en general, y entre las empresas y sus directivos en particular. 4) Una consolidación de la voz de las partes interesadas, es decir, de los consumidores, los trabajadores, las organizaciones de la sociedad civil interesadas en la empresa, sean medioambientales, de Derechos Humanos, de desarrollo etc. 5) Una mediación entre éstas y las empresas, mediante la creación de instrumentos de deliberación y concertación. 6) Los poderes públicos tienen también que impulsar dentro del mismo Estado, en todas sus actividades económicas, empresas públicas y organismos públicos las mismas pautas de conducta responsable que intenta promover en la sociedad. 7) Finalmente, los poderes públicos tienen que utilizar los criterios de la Responsabilidad Social como guía para toda la normativa administrativa, con el fin de proteger, entre otros, los derechos de los consumidores, no permitir las agresiones a los derechos humanos, alcanzar la máxima observancia de estándares laborales dignos y no discriminatorios [...]».

RESPONSABILIDAD SOCIAL Y RELACIONES LABORALES EN ESPAÑA 
Finalmente, este mismo documento destacaba —en conexión con lo ya visto- la necesidad de estimular a las empresas para elaborar informes de prácticas de RSE, mediante, entre otras medidas, apoyo técnico, catálogos de herramientas, buenas prácticas de información, etcétera; la conveniencia de prestar una especial atención a las PYMES con herramientas y medidas específicamente pensadas para ellas, y el interés de fomentar la participación de todos los agentes interesados mediante redes y, en especial, mediante el Consejo Estatal de RSE como órgano colegiado asesor y consultivo del gobierno. Pero sobre este consejo, su composición y sus funciones volveremos algo más tarde.

En definitiva, y como puede observarse, se detalla una amplia batería de medidas que presentaban evidentes concordancias con las recogidas en el Informe de la Subcomisión del Congreso, y que constituyen y deben constituir el referente de las políticas de fomento de la RSE en nuestro país.

\section{II.1.4. La promoción legal de la RSE: en especial, la Ley de Contratos del Sector Público y la Ley Orgánica para la Igualdad Efectiva entre Mujeres y Hombres}

En este contexto, y llegada ya esta «mayoría» de edad conceptual de la RSE en España, no resulta extraño que haya comenzado a incorporarse de forma más o menos matizada a algunos textos legales.

Dejando a un lado otras normas que podrían conectarse - básicamente por la cercanía de sus fines - con el desarrollo de la RSE, lo cierto es que seguramente han sido dos los campos que mayor atención doctrinal han suscitado en estos últimos años. En primer lugar, la posibilidad de utilizar la contratación pública como mecanismo de fomento de la responsabilidad social, mediante la inclusión de lo que se han dado en llamar «cláusulas sociales»y, más recientemente, «medioambientales». Y en segundo lugar, la expresa atención que ha merecido la responsabilidad social como mecanismo de fomento de una actuación socialmente responsable en la lucha por la igualdad entre mujeres y hombres. Pero vayamos por partes.

Por lo que se refiere a la primera cuestión, por todos es sabido cómo la contratación pública ha representado tradicionalmente uno de los mecanismos para lograr la implantación de ciertas condiciones dignas de trabajo ${ }^{62}$. Sin embargo, la incorporación de España a la Unión Europea y su normativa sobre contratación pública suscitó, en no pocas ocasiones, dudas sobre la viabilidad o no de la inclusión de cláusulas sociales entre las condiciones de ejecución o como criterio de adjudicación en la contratación pública ${ }^{63}$, tema este en el que la labor del Tribunal de Justicia de la Unión — antiguo Tribunal de Justicia de

62 Véase, obviamente, el Convenio 94 de la OIT relativo a las cláusulas de trabajo en los contratos celebrados por las autoridades públicas de 1949 y ratificado por España el 5 de mayo de 1971.

63 Por mencionar solo un ejemplo véase ROMÁN VACA, E. «Las cláusulas sociales en la licitación pública y la aplicación del ¿aberrante? Derecho comunitario». Revista de Derecho Social, № 36, 2006. 
las Comunidades Europeas- ha sido necesariamente determinante ${ }^{64}$, al igual que seguramente lo será la nueva regulación contemplada en la Directiva 2004/18/CE ${ }^{65}$.

Simplificando enormemente la cuestión, podríamos señalar que esta directiva parece permitir la inclusión de exigencias medioambientales y/o sociales en las especificaciones técnicas y en la verificación de la aptitud y selección de los participantes ${ }^{66}$, en el momento de la ejecución del contrato ${ }^{67}$ o en los criterios de adjudicación, siempre que estuvieran

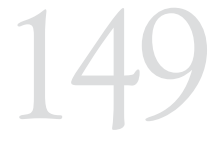

RESPONSABI-

LIDAD SOCIAL Y RELACIONES LABORALES EN ESPAÑA

64 En este sentido, podríamos resumir la doctrina más importante sobre esta materia siguiendo los siguientes documentos: AUTORES VARIOS. Libro Blanco sobre la calidad en el empleo en Andalucía. Estabilidad y seguridad laboral. Sevilla: CARL, 2005, p. 232; y Dictamen del Consejo de Estado 1638/2005 del 13 de octubre de 2005. Señalamos cómo la «jurisprudencia del Tribunal de Justicia de las Comunidades Europeas ha permitido una cierta apertura a los criterios sociales en fase de adjudicación, aunque con matices. En su Sentencia de 21 de septiembre de 1988, en el asunto 31/87: Gebroeders Beentjes, el Tribunal estimó que el criterio de contratar a desempleados de larga duración -que no guardaba relación ni con la comprobación de la solvencia ni con los criterios de adjudicación enumerados en la Directiva - era no obstante compatible con las Directivas de contratación pública si se atenía a todos los criterios pertinentes de Derecho comunitario. En la Sentencia de 26 de septiembre de 2000, en el asunto C-225/98: Comisión contra República Francesa, Construcción de edificios escolares en la región Nord-Pas-de-Calais, se afirmó que los poderes adjudicadores pueden basarse en una condición vinculada a la lucha contra el desempleo, siempre que ésta se atenga a todos los principios fundamentales del Derecho comunitario y que los poderes adjudicadores tengan ante sí dos o más ofertas económicamente equivalentes. En fin, en la Sentencia de 17 de septiembre de 2002, asunto C-513/99: Concordia Bus Finland, el Tribunal ha afirmado que cuando una entidad adjudicadora decide adjudicar un contrato al licitador que ha presentado la oferta económicamente más ventajosa, puede tener en cuenta criterios relativos a la conservación del medio ambiente [por analogía podría aplicarse a criterios sociales] siempre que tales criterios estén relacionados con el objeto del contrato, no atribuyan a dicha entidad una libertad incondicional de elección, se mencionen expresamente en el pliego de condiciones o en el anuncio de licitación y respeten todos los principios fundamentales del Derecho comunitario y, en particular, el principio de no discriminación». Aunque algo antigua, sigue siendo de interés la Comunicación Interpretativa de la Comisión sobre la Legislación Comunitaria de Contratos Públicos y las Posibilidades de Integrar los Aspectos Medioambientales en la Contratación Pública, Bruselas, 4.7.2001 COM (2001), 274 final, disponible en <http://eur-lex.europa. eu/LexUriServ/LexUriServ.do?uri=COM:2001:0274:FIN:ES:PDF>.

65 Directiva 2004/18/CE del Parlamento Europeo y del Consejo del 31 de marzo de 2004 sobre coordinación de los procedimientos de adjudicación de los contratos públicos de obras, de suministro y de servicios. Téngase también en cuenta la Directiva 2004/17/CE, relativa a los «sectores especiales" del agua, la energía, los transportes y los servicios postales. Obsérvese que ya desde su preámbulo la propia directiva señala que «[ella] está basada en la jurisprudencia del Tribunal de Justicia, en particular la relativa a los criterios de adjudicación, que clarifica las posibilidades con que cuentan los poderes adjudicadores para atender las necesidades de los ciudadanos afectados, sin excluir el ámbito medioambiental o social, siempre y cuando dichos criterios estén vinculados al objeto del contrato, no otorguen al poder adjudicador una libertad de elección ilimitada, estén expresamente mencionados y se atengan a los principios fundamentales [del Derecho comunitario]".

66 «Los poderes adjudicadores que deseen introducir necesidades medioambientales en las especificaciones técnicas de un contrato determinado podrán prescribir las características medioambientales, tales como un método de producción dado, y/o los efectos medioambientales específicos de grupos de productos o servicios. Podrán utilizar, aunque no están obligados a hacerlo, las especificaciones adecuadas definidas por las etiquetas ecológicas, como la etiqueta ecológica europea, la etiqueta ecológica (pluri) nacional o cualquier otra etiqueta ecológica, si las exigencias de la etiqueta se desarrollan y adoptan basándose en una información científica mediante un proceso en el que puedan participar todas las partes implicadas, como son los organismos gubernamentales, consumidores, fabricantes, distribuidores y organizaciones medioambientales, y si la etiqueta es accesible y está a disposición de todas las partes interesadas. En la medida de lo posible, los poderes adjudicadores deben establecer especificaciones técnicas con el fin de tener en cuenta los criterios de accesibilidad para personas con discapacidades o el diseño para todos los usuarios. Dichas especificaciones técnicas deben indicarse claramente, de modo que todos los licitadores sepan qué abarcan los requisitos establecidos por el poder adjudicador». Véase en concreto el artículo 23.3.b, 23.6, de la mencionada directiva. En relación con la presencia de elementos sociales entre los indicadores de capacidad técnica y profesional, véanse el artículo 44.2 en relación con el 48 y el 50 de la misma directiva.

67 Artículo 26, condiciones de ejecución del contrato: «Los poderes adjudicadores podrán exigir condiciones especiales en relación con la ejecución del contrato siempre que éstas sean compatibles con el Derecho comunitario y se indiquen en el anuncio de licitación o en el pliego de condiciones. Las 
«vinculados al objeto del contrato, no otorguen al poder adjudicador una libertad de elección ilimitada, estén expresamente mencionados y se atengan a los principios fundamentales» del Derecho comunitario ${ }^{68}$.

En este contexto, la reciente Ley 30/2007 del 30 de octubre sobre Contratos del Sector Público ${ }^{69}$ ha pretendido abordar esta cuestión (artículo 102) al prever, en primer lugar, la posibilidad de que:

[...] los órganos de contratación puedan establecer condiciones especiales de ejecución en relación con la ejecución del contrato, siempre que sean compatibles con el Derecho comunitario y se indiquen en el anuncio de licitación y en el pliego o en el contrato. Estas condiciones de ejecución podrían referirse, en especial, a consideraciones de tipo medioambiental o a consideraciones de tipo social, con el fin de promover el empleo de personas con dificultades particulares de inserción en el mercado laboral, eliminar las desigualdades entre el hombre y la mujer en dicho mercado, combatir el paro, favorecer la formación en el lugar de trabajo, u otras finalidades que se establezcan con referencia a la estrategia coordinada para el empleo o a garantizar el respeto a los derechos laborales básicos a lo largo de la cadena de producción mediante la exigencia del cumplimiento de las Convenciones fundamentales de la Organización Internacional del Trabajo ${ }^{70}$.

condiciones en que se ejecute un contrato podrán referirse, en especial, a consideraciones de tipo social y medioambiental». De forma más clara, el considerando 33 especifica que «las condiciones de ejecución de un contrato serán compatibles con la presente Directiva siempre y cuando no sean directa o indirectamente discriminatorias y se señalen en el anuncio de licitación o en el pliego de condiciones. En particular, pueden tener por objeto favorecer la formación profesional en el lugar de trabajo, el empleo de personas que tengan especiales dificultades de inserción, combatir el paro o proteger el medio ambiente. Como ejemplo se pueden citar, entre otras, las obligaciones - aplicables a la ejecución del contrato- de contratar a desempleados de larga duración o de organizar acciones de formación para los desempleados o los jóvenes, de respetar en lo sustancial las disposiciones de los convenios fundamentales de la Organización Internacional del Trabajo (OIT) en el supuesto de que éstos [sic] no se hubieran aplicado en el Derecho nacional, de contratar a un número de personas discapacitadas superior al que exige la legislación nacional». Igualmente, el preámbulo autoriza "en los casos oportunos en que la naturaleza de las obras y/o de los servicios justifique la aplicación de medidas o sistemas de gestión medioambiental en el momento de la ejecución del contrato público, podrá exigirse la aplicación de este tipo de medidas o sistemas [...]".

68 «A fin de garantizar la igualdad de trato, los criterios de adjudicación deben permitir comparar las ofertas y evaluarlas de manera objetiva. Si se reúnen estas condiciones, determinados criterios de adjudicación económicos y cualitativos, como los que se refieren al cumplimiento de las exigencias medioambientales, podrán permitir que el poder adjudicador satisfaga las necesidades del público afectado, tal como se definieron en las especificaciones del contrato. En estas mismas condiciones, el poder adjudicador podrá regirse por criterios destinados a satisfacer exigencias sociales que, en particular, respondan a necesidades - definidas en las especificaciones del contrato- propias de las categorías de población especialmente desfavorecidas a las que pertenezcan los beneficiarios/ usuarios de las obras, suministros y servicios que son objeto del contrato". Véase en este sentido el artículo 53, criterios de adjudicación del contrato: «1. Sin perjuicio de las disposiciones legales, reglamentarias o administrativas nacionales relativas a la remuneración de determinados servicios, los criterios en que se basarán los poderes adjudicadores para adjudicar los contratos públicos serán: a) bien, cuando el contrato se adjudique a la oferta económicamente más ventajosa desde el punto de vista del poder adjudicador, distintos criterios vinculados al objeto del contrato público de que se trate: por ejemplo, la calidad, el precio, el valor técnico, las características estéticas y funcionales, las características medioambientales, el coste de funcionamiento, la rentabilidad, el servicio posventa y la asistencia técnica, la fecha de entrega y el plazo de entrega o de ejecución».

69 BOE № 261 del 31 octubre de 2007.

70 El mismo precepto continúa señalando que «los pliegos o el contrato podrán establecer penalidades, conforme a lo prevenido en el artículo 196.1, para el caso de incumplimiento de estas condiciones especiales de ejecución, o atribuirles el carácter de obligaciones contractuales esenciales a los efectos señalados en el artículo 206.g. Cuando el incumplimiento de estas condiciones no se 
En segundo lugar, el artículo 134 de la Ley 20/2007 —referido a los criterios de valoración de las ofertas, y que amplía lo establecido en la normativa comunitaria, meramente ejemplificativa - establece que:

[...] para la valoración de las proposiciones y la determinación de la oferta económicamente más ventajosa deberá atenderse a criterios directamente vinculados al objeto del contrato, tales como la calidad, el precio, la fórmula utilizable para revisar las retribuciones ligadas a la utilización de la obra o a la prestación del servicio, el plazo de ejecución o entrega de la prestación, el coste de utilización, las características medioambientales o vinculadas con la satisfacción de exigencias sociales que respondan a necesidades, definidas en las especificaciones del contrato, propias de las categorías de población especialmente desfavorecidas a las que pertenezcan los usuarios o beneficiarios de las prestaciones a contratar, la rentabilidad, el valor técnico, las características estéticas o funcionales, la disponibilidad y coste de los repuestos, el mantenimiento, la asistencia técnica, el servicio postventa u otros semejantes ${ }^{71}$.

Y finalmente, la Disposición Adicional Sexta establece la posibilidad, en primer lugar, de incorporar un criterio de preferencia - a igualdad de proposiciones - para las empresas que tengan en su plantilla una cantidad superior al $2 \%$ de trabajadores con discapacidad, con preferencia, en caso de que hubiera varias, hacia el licitador en cuya plantilla dispusiera del mayor porcentaje de trabajadores fijos con discapacidad. Una preferencia similar - esto es, siempre que exista igualdad de condiciones con las que sean económicamente más ventajosas- se establece, en segundo lugar, para las proposiciones presentadas por aquellas empresas dedicadas específicamente a la promoción y a la inserción laboral de personas en situación de exclusión social; se valoraría el compromiso

tipifique como causa de resolución del contrato, el mismo podrá ser considerado en los pliegos o en el contrato, en los términos que se establezcan reglamentariamente, como infracción grave a los efectos establecidos en el artículo 49.2.e». Un excelente análisis de esta norma es el de GALA DURÁN, C. «Responsabilidad social empresarial, derecho a la libre prestación de servicios y contratación pública», de próxima publicación en Relaciones Laborales. En la doctrina, por todos, RODRíGUEZ EsCANCIANO, S. Cláusulas sociales y licitación pública: análisis jurídico. Andalucía: Instituto Andaluz de Administración Pública, 2008, pp. 170 y siguientes.

71 Sobre el cambio que esta norma supone sobre la situación anterior puede consultarse, por todos, Rodríguez Escanciano. Cláusulas sociales... Óp. cit., p. 157, quien, no obstante, destaca también sus importantes limitaciones. Al margen de la posibilidad de incluir este tipo de cláusulas sociales, ya había sido admitida por el Tribunal Supremo (Sala de lo Contencioso-Administrativo, Sección 4ª en su sentencia del 27 junio 2006 (RJ 2006/6108 - Rec. 337/2004), en relación con la Sentencia del Tribunal Superior de Justicia de Madrid, № 606/2003 del 30 de mayo (JUR 2004\156948). En esta misma línea de aceptación se movía, además, el Consejo de Estado en su Dictamen $3.495 / 98$ del 19 de noviembre de 1998, en el cual se señalaba que estos criterios sociales «no dejan de ser objetivos ni de estar referidos a la oferta más ventajosa para los intereses públicos, porque una de las posibles manifestaciones de seriedad y fiabilidad de una empresa puede ser precisamente la estabilidad y calidad de los contratos que ofrece a sus empleados, pudiendo ser un criterio objetivo para la adjudicación, incluso más fiable que otros señalados en el artículo 87, para seleccionar - siempre haciendo uso de una ponderación razonable del criterio - al contratista que corresponda, precisamente para proteger los intereses públicos presentes en la selección de la oferta más ventajosa, dado que la calidad del empleo ofrecido por una empresa, y la cualificación de sus recursos humanos, es uno de los factores objetivos que puede influir en la selección del contratista más adecuado». 
formal del licitador de contratar no menos del 30\% de sus puestos de trabajo con personas pertenecientes a colectivos con riesgo de exclusión social $^{72}$, cuya situación será acreditada por los servicios sociales públicos competentes.

En tercer lugar, y de forma más específica, la misma norma establece que, para «los contratos relativos a prestaciones de carácter social o asistencial», pueden priorizarse, con la misma forma y condiciones, «las proposiciones presentadas por entidades sin ánimo de lucro, con personalidad jurídica, siempre que su finalidad o actividad tenga relación directa con el objeto del contrato, según resulte de sus respectivos estatutos o reglas fundacionales y figuren inscritas en el correspondiente registro oficial».

Y ya por último, la DA 6 Ley 30/2007 concluye señalando que:

[...] los órganos de contratación podrán señalar en los pliegos de cláusulas administrativas particulares la preferencia en la adjudicación de los contratos que tengan como objeto productos en los que exista alternativa de Comercio Justo para las proposiciones presentadas por aquellas entidades reconocidas como Organizaciones de Comercio Justo, siempre que dichas proposiciones igualen en sus términos a las más ventajosas desde el punto de vista de los criterios que sirvan de base para la adjudicación ${ }^{73}$.

Sea como fuere, y dejando a un lado el impacto que sobre estas cuestiones puede tener la reciente Sentencia del TJUE Rüffert ${ }^{74}$, de lo que no cabe duda es que la llamada más clara en este punto de la normativa legal a la RSE se produce en la Ley Orgánica 3/2007 del 22 de marzo, para la igualdad efectiva entre mujeres y hombres ${ }^{75}$. Esta ley, que nace con la clara y expresa vocación «de erigirse en la ley-código de la igualdad entre mujeres y hombres» al adoptar un claro enfoque trasversal, utiliza, como una más de las herramientas destinadas a lograr la plena igualdad entre mujeres y hombres, la responsabilidad social ${ }^{76}$.

72 La norma se refiere expresamente a perceptores de rentas mínimas de inserción, o cualquier otra prestación de igual o similar naturaleza, según la denominación adoptada en cada comunidad autónoma; a personas que no puedan acceder a las prestaciones antes citadas por falta del período exigido de residencia o empadronamiento o por haber agotado el período máximo de percepción legalmente establecido; a jóvenes mayores de 18 años y menores de 30 , procedentes de instituciones de protección de menores; a personas con problemas de drogadicción o alcoholismo que se encuentren en procesos de rehabilitación o reinserción social; a internos de centros penitenciarios cuya situación penitenciaria les permita acceder a un empleo, así como a liberados condicionales y ex reclusos. Finalmente, también se mencionan las personas con discapacidad.

73 Sobre esta Disposición Adicional, por todos, RODRíguEZ EscANCIANO. Cláusulas sociales...Óp. cit., pp. 36 y siguientes.

74 STJCE del 3 de abril de 2008, Case C-346/06, Dirk Rüffert, v. Land Niedersachsen, disponible en <http://eur-lex.europa.eu/LexUriServ/LexUriServ.do?uri=CELEX:62006J0346:EN:HTML>. Sobre este tema, véanse nuevamente las interesante observaciones de GALA DURÁN. «Responsabilidad social empresarial...». Óp. cit., pp. 20 y siguientes del original impreso.

75 BOE № 71 del 23 de marzo de 2007.

76 Véase García NinET, J.I. (director) y A. GARRIGUES GimÉNEZ (coordinadora). Comentarios a la Ley de Igualdad: Ley orgánica 3/2007, de 22 de marzo para la igualdad efectiva de mujeres y hombres. Valencia: CISS, 2007; y SALA T. et al. (coordinadores). Comentarios a la Ley orgánica 3/2007, de 22 de marzo, para la igualdad efectiva de mujeres y hombres. Madrid: La Ley, 2008. 
Y para ello, ha establecido - de forma similar a lo que antes hemos visto- la posibilidad de incorporar condiciones específicas de ejecución de los contratos públicos, con el fin de promover la igualdad entre mujeres y hombres en el mercado de trabajo ${ }^{77}$, o - nuevamente de forma similar a lo que ya hemos visto- la posibilidad de establecer en los pliegos de cláusulas administrativas particulares la preferencia en la adjudicación de los contratos de las proposiciones presentadas por aquellas empresas que, en el momento de acreditar su solvencia técnica o profesional, cumplan con las directrices antes señaladas, siempre que estas proposiciones igualen en sus términos a las más ventajosas desde el punto de vista de los criterios objetivos que sirvan de base a la adjudicación ${ }^{78}$.

Yendo un paso más allá, esta norma incorpora expresamente un título específico, el VII, dedicado monográficamente a la «Igualdad en la responsabilidad social de las empresas» ${ }^{79}$. Este está compuesto por tres artículos. El primero (artículo 73) establece que «las empresas podrán asumir la realización voluntaria de acciones de responsabilidad social, consistentes en medidas económicas, comerciales, laborales, asistenciales o de otra naturaleza, destinadas a promover condiciones de igualdad entre las mujeres y los hombres en el seno de la empresa o en su entorno social». La realización de estas acciones — continúa el precepto- «podrá ser concertada con la representación de los trabajadores y las trabajadoras, las organizaciones de consumidores y consumidoras y usuarios y usuarias, las asociaciones cuyo fin primordial sea la defensa de la igualdad de trato entre mujeres y hombres y los Organismos de Igualdad [sic]». Se trata ciertamente de un amplio elenco de sujetos «negociadores» - sobre todo si lo comparamos con el Proyecto de 2002 - , y que solo puede comprenderse, al menos a nuestro juicio, si atribuimos esta posibilidad a cada grupo de interés en relación con su concreta área de interés. En cualquier caso, este posible diálogo con otros grupos de interés no impediría que, como mínimo, se informe «a los representantes de los trabajadores de las acciones que no se concierten con los mismos [sic] $»^{80}$.

Finalmente, esta norma concluye con una (aparente) superflua referencia a que «las decisiones empresariales y acuerdos colectivos relativos a medidas laborales les será de aplicación la normativa laboral», referencia que, al menos a mi juicio, solo viene a abordar una cuestión por lo demás discutida: la posibilidad de incorporar medidas de responsabilidad social en acuerdos o convenios firmados con los representantes de

77 Véanse los artículos 33 y 34.1 LO 3/2007 del 22 de marzo para la igualdad efectiva de mujeres y hombres.

78 Véase el artículo 34.2 LO 3/2007 del 22 de marzo para la igualdad efectiva de mujeres y hombres. En la doctrina, por todos, GALA DURÁN. «Responsabilidad social empresarial...». Óp. cit., p. 13 del original impreso.

79 Sobre este, y por todos, véase PÉreZ YAÑEZ, R. M. «Responsabilidad Social de la Empresa e igualdad de género". En AUtORES VARIOS. Anuario de Conferencias CARL. I Semestre, 2008; BAZ TEJEDOR, J.A. «Responsabilidad Social Empresarial Laboral: especial referencia a la LO 3/2007, de 22 de marzo, para la igualdad efectiva de mujeres y hombres". En <https://www.juntadeandalucia.es/ empleo/responsabilidad/admin/downloads/descargar.php?id=341>.

80 Obsérvese sea cual sea el objeto o el grupo de interés afectado por la medida. 
los trabajadores. Y ello porque pensar, como muchos sostienen, que lo contenido en un convenio, o acuerdo de empresa, nunca puede considerarse muestra de la responsabilidad social del empresario — al ser solo, se dice, cumplimiento de lo pactado y, por ende, al faltar los rasgos de unilateralidad y adicionalidad ${ }^{81}$ — olvida, al menos a mi juicio, las peculiaridades propias del ámbito laboral. Este es un ámbito en el cual el diálogo con el stakeholder concreto - los sindicatos y los representantes de los trabajadores en sentido amplio- está legalmente regulado, y en el cual, además, y al menos en el caso español, los posibles acuerdos alcanzados con ellos están dotados de fuerza vinculante por expreso mandato constitucional (artículo 37 de la Constitución Española) ${ }^{82}$.

En este contexto, negar la posibilidad de que ciertas medidas de responsabilidad social se incorporen a acuerdos y convenios de empresa, siempre que, claro está, se sitúen por encima de lo establecido legal y sectorialmente, no solo olvida estas singularidades — de hecho, nadie discutiría que medidas medioambientales pactadas con grupos de interés fueran formas de responsabilidad social—, sino que además:

- en primer lugar, puede llevarnos a auténticas paradojas - por ejemplo, que un empresario que no acuerda sino que simplemente informa a los representantes de estas medidas impuestas unilateralmente pueda ser considerado socialmente responsable, en tanto que otro que no solo informa sino que negocia y acuerda, y que en consecuencia las dota de mayor fuerza de obligar, no lo sea-; o

- en segundo lugar, que se plantee igualmente el contrasentido de que un concepto nacido para incorporar las demandas de grupos de interés a los objetivos de la empresa, a través de un diálogo claro y profundo, fomentaría precisamente lo contrario: esto es, la reducción del papel del diálogo y, en este caso concreto, del acuerdo, con los grupos de interés en este proceso.

Por ello, la concreta formalización en, por ejemplo, un acuerdo de empresa de un plan de igualdad, allí donde no es exigible legalmente, no debe ser un criterio determinante para rechazar la posible responsabilidad social del empleador. Lo importante, repito, sería la calidad del diálogo, la mayor y más incisiva participación del concreto grupo de interés y, por supuesto, el hecho de que tal acuerdo suponga, por parte del empresario, ir más allá de sus anteriores obligaciones legales y convencionales-sectoriales.

81 Sobre el tema, véase PÉREZ YaÑEZ. «Responsabilidad Social...». Óp. cit., pp. 530-531. Desde una perspectiva más matizada, SePÚlvedA GómEZ, M. «Negociación Colectiva y Responsabilidad Social de las Empresas". En AUtORES VARIOS. Anuario de Conferencias... Óp. cit., pp. 129 y siguientes.

82 Véase DEL REY GUANTER, S. «Responsabilidad social empresarial y orden social: algunas reflexiones sobre sus conexiones semánticas (o terminológicas) y sustanciales». En AUTORES VARIOS. La responsabilidad social empresarial... Óp. cit., p. 49. En este documento se menciona que «en este sentido hay que partir de la base de la idoneidad de la negociación colectiva para acometer, como fuente de regulación, contenidos propios de la RSE [...]». 
Finalmente, y dejando a un lado el artículo 75 relativo la participación de las mujeres en los consejos de administración de las sociedades mercantiles - una cuestión, por lo tanto, bastante lejana a la que ahora nos ocupa-, bastará señalar que el artículo 74 LO 3/2007 reconoce la posibilidad de que las empresas puedan hacer un uso publicitario de sus acciones de responsabilidad en materia de igualdad, de acuerdo con las condiciones establecidas en la legislación general de publicidad. Dispondrían, no obstante, que «el Instituto de la Mujer, u órganos equivalentes de las Comunidades Autónomas, estarán legitimados para ejercer la acción de cesación cuando consideren que pudiera haberse incurrido en supuestos de publicidad engañosa».

En este sentido, el reciente Real Decreto 1615/2009, del 26 de octubre, regula la concesión y utilización del distintivo «Igualdad en la Empresa» ${ }^{83}$. Tampoco cabe olvidar la aparición de sucesivas órdenes destinada a establecer las bases reguladoras de la concesión de subvenciones a las actividades de promoción de, entre otras cuestiones, la responsabilidad social de las empresas ${ }^{84}$.

\section{II.1.5. El Consejo Estatal de RSE}

El último paso en este proceso de progresiva integración de la RSE en nuestro país se centraría, al menos por el momento ${ }^{85}$, en la creación del Consejo Estatal de RSE mediante el Real Decreto 221/2008 del 15 de febrero.

De hecho, la creación de este consejo había sido postulada por múltiples instancias. Así, el Pleno del Senado, el 29 de mayo de 2007, ya había aprobado una moción por la que se instaba al Gobierno a crear un consejo de $\mathrm{RSE}^{86}$. Y esta misma idea, algo más desarrollada, aparecía igualmente tanto en el Informe de Expertos del Ministerio de Trabajo antes mencionado, como en la Declaración de los Interlocutores Sociales en el Marco del Diálogo Social, de diciembre de 2007, sobre la que volveremos inmediatamente.

Dejando a un lado las reglas de funcionamiento de un órgano que puede actuar en pleno, comisiones o grupos de trabajo, nos limitaremos a señalar que este consejo se configura como un órgano colegiado interministerial, de carácter asesor y consultivo del Gobierno, de

83 Sobre estos distintivos, si bien previo a la aprobación de la mencionada norma, véase BALLESTER PASTOR, I. «El distintivo de calidad empresarial como manifestación de la responsabilidad social corporativa y su repercusión en las prácticas empresariales defensoras de la igualdad de oportunidades. Estudio de Derecho internacional y comunitario». Revista del Ministerio de Trabajo y Asuntos Sociales, № 67, pp. 175 y siguientes.

84 Véase, por mencionar solo el último ejemplo, la Orden TIN/3440/2009 del 16 de diciembre, BOE del 21 de diciembre de 2009.

85 Dejando a un lado algunas recientes proposiciones no de ley, como aquella sobre la RSE (162/000322) presentada por el Grupo Socialista (BOCG. Congreso de los Diputados № D-151 del 20 de febrero de 2009) y aquella relativa a adopción de medidas para promover la responsabilidad social de las empresas (BOCG. Congreso de los Diputados № D-95 del 31 de octubre de 2008). La aprobación del texto transaccional de la primera -incorporando en gran medida la segunda- se halla en DS. Congreso de los Diputados № 93 del 23 de junio de 2009.

86 Como un foro de encuentro de todas las partes interesadas, que mantuviera un diálogo multilateral permanente sobre la RSE y propusiera al Gobierno acciones para su fomento. 
composición cuatripartita y paritaria ${ }^{87}$, que se adscribe al Ministerio de Trabajo y Asuntos Sociales, a través de la Secretaría General de Empleo - y, más en concreto, a la actual Dirección General de la Economía Social del Trabajo Autónomo y de la $\mathrm{RSE}^{88}$ _ , y que estará encargado del impulso y del fomento de las políticas de RSE.

En concreto, su norma de creación le atribuye (artículo 4) cinco amplios objetivos:

- en primer lugar, constituir un foro de debate sobre RSE entre las organizaciones empresariales y sindicales más representativas, administraciones públicas y otras organizaciones e instituciones de reconocida representatividad en este ámbito, que sirva como marco de referencia para el desarrollo de esta forma de gestión empresarial;

- en segundo lugar, realizar una actividad de fomento de las iniciativas sobre RSE, al proponer al Gobierno posibles medidas en este sentido y prestar atención especial a la singularidad de las pymes;

- en tercer lugar — como es típico dada su naturaleza-, informar, en su caso, sobre las iniciativas y regulaciones públicas que afecten a las actuaciones de empresas, organizaciones e instituciones públicas y privadas en este ámbito;

- en cuarto lugar, analizar el desarrollo de la RSE en España, la Unión Europea y países terceros, e informar sobre actuaciones en esta materia; y

87 De acuerdo con la actual redacción del artículo 5 del mencionado Real Decreto 221/2008 del 15 de febrero, modificado por el Real Decreto 1469/2008 del 5 de septiembre, la composición del mencionado órgano será la siguiente: la presidencia corresponderá al Ministro de Trabajo e Inmigración. Además, se integrará por catorce vocales en representación de las organizaciones empresariales más representativas; catorce vocales en representación de las organizaciones sindicales más representativas; catorce vocales en representación de otras organizaciones e instituciones de reconocida representatividad e interés en el ámbito de la RSE. A estos efectos, se tendrán en cuenta los representantes de organizaciones no gubernamentales que reúnan, entre otros, los siguientes criterios: experiencia y actuación en distintos aspectos de la responsabilidad social, dimensión geográfica de sus actividades y volumen de recursos destinados a ellas. También se tendrá en cuenta, entre otros, a los representantes de las asociaciones, consejos $u$ organizaciones de los campos de los consumidores, el medio ambiente, la discapacidad y la economía social. Asimismo, se considerarán los representantes de instituciones académicas reconocidas por su actividad docente, de investigación y de asesoramiento en este ámbito, y las fundaciones o asociaciones dedicadas específicamente a cuestiones de RSE. Finalmente, también estarán presentes catorce vocales en representación de las administraciones públicas, de los cuales diez serán de la Administración General del Estado, uno por cada uno de los Ministerios de Asuntos Exteriores y de Cooperación, de Economía y Hacienda, de Educación, Política Social y Deporte, de Trabajo e Inmigración, de Medio Ambiente, y Medio Rural y Marino, de Industria, Turismo y Comercio, de Sanidad y Consumo, de Administraciones Públicas, de Igualdad y de la Oficina Económica del Presidente del Gobierno, con rango de Director General, salvo en el caso del Ministerio de Trabajo e Inmigración, que será el titular de la Secretaría General de Empleo; tres serán en representación de las comunidades autónomas y de las ciudades de Ceuta y Melilla, designados por la Conferencia Sectorial de Asuntos Laborales, y uno será en representación de la asociación de entidades locales más representativa de ámbito estatal.

88 Véase el Real Decreto 1469/2008 del 5 de septiembre, mediante el que se modifica el Real Decreto $221 / 2008$ del 15 de febrero, por el que se crea y regula el Consejo Estatal de Responsabilidad Social de las Empresas. Igualmente, debe consultarse el Real Decreto 1129/2008 del 4 de julio, por el que se desarrolla la estructura orgánica básica del Ministerio de Trabajo e Inmigración y se modifica el Real Decreto 438/2008 del 14 de abril, por el que se aprueba la estructura orgánica básica de los departamentos ministeriales. 
- por último, y lo que es más llamativo, «promocionar estándares y/o características de las memorias y/o informes de Responsabilidad Social de las Empresas y de sostenibilidad, así como herramientas más adecuadas para su elaboración y seguimiento», para lo cual se constituye (artículo 5) como Observatorio de la Responsabilidad Social de las Empresas en España.

De esta forma, el consejo se configura como órgano central de participación en materia de RSE, al que se unen otros foros - que parece necesario al menos mencionar-como la red de RSE de ámbito local RETOS, auspiciada por el Ministerio de Trabajo e Inmigración, y que cuenta con distintos representantes de administraciones públicas de ámbito local y regional con el objetivo de fomentar el mutuo aprendizaje y la acción conjunta en el impulso de los territorios socialmente responsables ${ }^{89}$.

Volviendo al consejo, tras su creación y constitución —no exenta de cierta polémica $^{90}$ - quizás deba destacarse la reciente constitución, en su seno, de cinco grupos de trabajo centrados en diversos puntos: el papel de la RSE ante la crisis económica, su contribución al nuevo modelo productivo, la competitividad y el desarrollo sostenible; la transparencia, la comunicación y los estándares de los informes y de las memorias de sostenibilidad; el consumo y la inversión socialmente responsable; la RSE y la educación; y la gestión de diversidad, cohesión social y cooperación al desarrollo ${ }^{91}$.

\section{II.2. La actuación de los poderes autonómicos}

A lo largo de estos últimos años, han sido muchas las comunidades autónomas que, en el marco de las competencias atribuidas por la Constitución Española y distintos estatutos de autonomía, han apostado claramente por apoyar la responsabilidad social de sus empresas.

Intentando dar solo algunas pinceladas de un tema extraordinariamente amplio, podríamos decir que, en algunos casos, este apoyo se ha producido a través de la incentivación del diálogo social en su más alto nivel o a través de medidas de apoyo a actuaciones concretas de estas empresas. Ejemplos de estas vías de fomento serían, por mencionar algún caso, el de Galicia, donde, en el seno del Consejo Gallego de Relaciones Laborales, se ha firmado recientemente un acuerdo sobre esta materia ${ }^{92}$, del vocales y suplentes de los cuatro grupos del Consejo, salvo los pendientes de la Confederación Sindical de las Comisiones Obreras (CCOO) que, en aquel momento, se encontraba en actividad precongresual. Sobre estos temas es de interés el informe de actuaciones que puede consultarse en <http://www.mtas.es/es/empleo/economia-soc/RespoSocEmpresas/090128_INFOERME_RSE_ Subsecretario_2.pdf>.

91 Para más información, véase <http://www.mtas.es/es/empleo/economia-soc/RespoSocEmpresas/ observatorio.htm>.

92 «Acordo a Prol da Responsabilidade Social Empresarial en Galicia». El texto de este acuerdo puede obtenerse en <http://www.xunta.es/periodico/dialogo/pacto8.pdf>.

RESPONSABI-

LIDAD SOCIAL

Y RELACIONES

LABORALES EN

ESPAÑA 
mismo modo que también se han subvencionado actuaciones concretas en materia de RSE.

Otro ejemplo notable sería el de Aragón. Su ya lejana orden del 17 de octubre de 2002, emitida por el Departamento e Industria, Comercio y Desarrollo, convocaba la concesión de ayuda a empresas industriales aragonesas e incorporaba el concepto de responsabilidad social corporativa (RSC), y defendía que las «metodologías de RSC encierran una concepción de la actitud general de la actividad empresarial moderna y comprometida con su entorno». Las ayudas apostaban por el apoyo y por la puesta en marcha de políticas formales de acuerdo a iniciativas nacionales e internacionales; por la integración de la información económica, social y medioambiental en las memorias anuales de las empresas esto siguiendo el modelo propuesto por Global Reporting Initiative-; y por la obtención de certificación en normas como SA8000 o AA1000. Posteriormente, otras iniciativas la han seguido y destacaron, por ejemplo, el Premio Aragonés a la Responsabilidad Social Corporativa que, en 2006, ya se encontraba en su tercera convocatoria ${ }^{93}$; o las ayudas incorporadas a la Orden del 5 de diciembre de 2007, del Departamento de Industria, Comercio y Turismo, por la que se convocaban, para el ejercicio $2008^{94}$, ayudas destinadas a la incorporación del concepto de la RSC en la gestión empresarial ${ }^{95}$.

Otro ejemplo reciente sería el de la Rioja que, de acuerdo con la información suministrada por su página web $^{96}$, ha desarrollado un plan estratégico para el impulso de la responsabilidad social de sus empresas junto con otras medidas como la creación del Foro Riojano para la Responsabilidad Social ${ }^{97}$, la puesta en marcha de líneas de crédito a interés cero para la ejecución de proyectos en colaboración con Caja Rioja o la edición de manuales sobre RSE.

Finalmente, no quisiéramos dejar de señalar que algunas comunidades autónomas han optado por la creación de una dirección general específica sobre esta materia, como ocurre en el caso de las Islas Baleares ${ }^{98}$.

93 Véase el Decreto 12/2004 del 27 de enero del Gobierno de Aragón, mediante el que se instituía el Premio Aragonés a la Responsabilidad Social Corporativa.

94 BOA № 147 del 14 de diciembre de 2007.

95 En ella se subvencionaban una o varias de las acciones siguientes: la realización de estudios previos de viabilidad de la incorporación o realización de cualquiera de los tres apartados siguientes, y la puesta en marcha de códigos de conducta de acuerdo a iniciativas nacionales e internacionales que promuevan la responsabilidad social corporativa. Se consideran válidos los códigos que estén de acuerdo con las directrices de la OCDE para empresas multinacionales, principios del Global Compact de Naciones Unidas o compromisos equivalentes; la elaboración de la memoria anual de la sociedad de modo que en ella quede integrada la información económica, social y medioambiental, para lo cual se seguiría la pauta de lo que ha dado en llamarse «memorias de sostenibilidad», Global Report Iniciative o equivalente; la obtención de certificación en normas de reconocido prestigio nacional o internacional en materia de responsabilidad social (SA 8000, AA 1000, SGE 21 o equivalentes).

96 En <http://www.larioja.org/npRioja/default/defaultpage.jsp?idtab=431801>.

97 Decreto 26/2006 del 28 de abril, por el que se crea el Foro Riojano para la Responsabilidad Social (BOR № 58 del 2 de mayo de 2006).

98 Sobre la situación de la RSE en las Islas Baleares, puede consultarse el estudio La responsabilidad social empresarial en las Islas Baleares, cuyo resumen ejecutivo se halla en <http://www.caib.es/ govern/archivo.do?id=235505>. 
Mientras tanto, la Generalitat de Cataluña ha optado por una actuación que congrega iniciativas destinadas a la difusión de la responsabilidad social entre la sociedad catalana con otras relativas al impulso de políticas de RSE en empresas y organizaciones, con la promoción de la transparencia de las prácticas empresariales entre todos los grupos de interés, con la difusión de buenas prácticas de RSE mediante publicaciones, concursos, campañas de comunicación y jornadas, y, por último, con la concienciación de los consumidores respecto de la incorporación de criterios sociales y ambientales en la selección de sus proveedores y el impulso del modelo cooperativo como paradigma de empresa socialmente responsable.

Ya por último, en la Comunidad Autónoma de Andalucía, además de la labor desarrollada en el marco de las iniciativas EQUAL y del Grupo de Trabajo del Parlamento de Andalucía sobre RSE, cabe destacar, de un lado, la expresa mención a estos temas en la normativa sobre igualdad autonómica -algo por lo demás común a este tipo de normas en otras muchas comunidades ${ }^{99}$ - y, del otro, la atención prestada a estos temas en los últimos acuerdos de concertación social.

Así, en el VI Acuerdo de Concertación Social, se señalaba cómo «la promoción de la cultura de la responsabilidad social corporativa, en la actual sociedad, es un instrumento que junto a otros, permite avanzar en el logro de un mayor nivel de empleo en nuestra Comunidad Autónoma». En consecuencia, las partes firmantes acordaron apoyar todas aquellas «actuaciones precisas para un mayor desarrollo del binomio empleo-responsabilidad social corporativa». Asimismo, en el recientísimo VII Acuerdo de Concertación Social, acordaron continuar con el desarrollo de la RSE como elemento estratégico de un «nuevo modelo de empresa» que promoviese un cambio en el modelo productivo actual al incorporar elementos sociales y medioambientales en actividades y funciones tradicionales de las empresas andaluzas. El objeto de las nuevas medidas, acordadas en los órganos correspondientes, debería ser el impulso de la RSE por parte de las empresas andaluzas como valor añadido de sus productos y servicios, así como el fomento de prácticas de ética social y medioambiental dentro del marco del desarrollo sostenible definido por las instituciones de la Unión Europea ${ }^{100}$.

99 En el caso concreto de Andalucía, véase el artículo 34 de la Ley 12/2007 del 26 de noviembre para la promoción de la igualdad de género en Andalucía. Por mencionar el caso de otra comunidad autónoma, véanse los artículos 13 a 15 de la Ley 2/2007 del 28 de marzo acerca del trabajo en igualdad de las mujeres de Galicia. Consúltese un amplio e interesante estudio al respecto en GALA DURÁN. «Responsabilidad social empresarial...». Óp. cit., pp. 15 y siguientes del original impreso.

100 En este sentido, el VII Acuerdo de Concertación Social resalta que se activarán y reforzarán los valores de la RSE entre los emprendedores y emprendedoras, y que se potenciaría la estabilidad, la calidad y la igualdad en el empleo y, finalmente, las acciones informativas y formativas para dar a conocer y extender el modelo en las empresas públicas y privadas. Para ello se establecen los siguientes objetivos: activar y reforzar los valores de RSE entre las personas emprendedoras y las empresas, especialmente los relativos a la estabilidad, la calidad y la igualdad en el empleo, así como la cultura preventiva y la fluidez en el marco de las relaciones laborales con los trabajadores y trabajadoras; avanzar, dentro de las administraciones públicas, en el modelo de RSE. Además, y en el marco de estos objetivos, el VII Acuerdo de Concertación Social prevé las siguientes medidas:

RESPONSABI-

LIDAD SOCIAL

Y RELACIONES

LABORALES EN

ESPAÑA 

El papel y la función de la RSE en el sistema de relaciones laborales no ha dejado indiferente a los interlocutores sociales españoles ${ }^{101}$. De hecho, esta cuestión ha sido objeto de atención tanto en el diálogo social como en algunos de los últimos Acuerdos Interconfederales de Negociación Colectiva.

\section{III.1. La RSE en el diálogo social}

En este sentido, y por lo que se refiere al primer ámbito, la Comisión de Seguimiento y Evaluación del Diálogo Social, en su reunión del 2 de marzo de 2005, ya había considerado que, dentro de la orientación que debería tener la economía española hacia un modelo de crecimiento estable y sostenido, la RSE debería ser considerada dentro del marco de la Declaración para el Diálogo Social de 2004.

Desde esta premisa, la Comisión de Seguimiento y Evaluación del Diálogo Social, formada por representantes del Gobierno, Confederación Española de Organizaciones Empresariales (CEOE), Confederación Española de la Pequeña y Mediana Empresa (CEPYME), Confederación Sindical de Comisiones Obreras (CCOO) y Unión General de Trabajadores (UGT), aprobó finalmente en diciembre de 2007 un documento titulado «La Responsabilidad Social de las Empresas (RSE). Diálogo Social ${ }^{102}$. Este documento contempla dos grandes capítulos relativos, por una parte, al concepto y al ámbito de la RSE, y, por otra, a las políticas públicas sobre este tema. Y así, tras considerar a la RSE «como una contribución y una oportunidad para el desarrollo sostenible, el crecimiento económico y la cohesión social», la define como «un conjunto de compromisos de diverso orden económico, social y medioambiental adoptados por las empresas, las organizaciones e instituciones públicas y privadas y que constituyen un valor añadido al cumplimiento de sus obligaciones legales, contribuyendo a la vez, al progreso social y económico en el marco de un desarrollo sostenible». Se trata de una idea cuyos principios generales serían la voluntariedad; el valor añadido mensurable en relación con la atención prestada a los grupos de interés en función de la actividad desarrollada y su entorno; la integración y eficiencia; la adaptabilidad y flexibilidad; la credibilidad, transparencia, globalidad; y sus dimensiones y naturaleza social y medioambiental.

la creación, en el ámbito de la Junta de Andalucía, de un órgano en el que participen los agentes firmantes del acuerdo; la implantación de códigos de buenas prácticas en RSE y la creación de los premios andaluces que reconozcan las buenas prácticas en materia de RSE; el Programa de Impulso de la RSE en Andalucía, como valor añadido de los productos y servicios y de aquellas actuaciones de formación e información que faciliten una adecuada divulgación de la RSE en la sociedad andaluza; y el impulso de acciones de sensibilización sobre la responsabilidad social en materia de igualdad de género.

101 Sobre todas estas cuestiones, pero en especial sobre la posición de las principales organizaciones sindicales y empresariales españolas, véase ARAGÓN MEDINA y ROCHA SÁCHEZ. «Los actores de la responsabilidad social...». Óp. cit., pp. 156 y siguientes.

102 Disponible en <http://www.mtas.es/es/empleo/economia-soc/RespoSocEmpresas/docs/07_12_05_ RSE_DS.pdf>. 
Asimismo, con relación a las políticas públicas, se recogen diez propuestas que contemplan la mejora del conocimiento de la RSE y que parten de su vinculación con los factores de competitividad, con la creación de empleo, con la cohesión social y el medio ambiente. Estas se centran en el análisis y en la difusión de buenas prácticas; en el consumo responsable; en la promoción de las capacidades y competencias de los interlocutores sociales, al fomentar, entre otras iniciativas, la creación de foros y de redes de cooperación; en la modernización y la adaptación de las relaciones laborales; en el impulso del desarrollo sostenible; en el estímulo a las empresas para el informe de RSE; y en su fomento en el ámbito de las pymes. Y todo ello tras promover, como ya hemos visto, la creación del Consejo Estatal de RSE.

\section{III.2. La RSE en los Acuerdos Interconfederales de Nego- ciación Colectiva}

Tampoco los sucesivos acuerdos interconfederales, que desde 2002 orientan la negociación colectiva española, han sido inmunes al interés sobre la RSE.

El Acuerdo Interconfederal de Negociación Colectiva para el Año $2005^{103}$ — prorrogado para el año 2006 - abordaba esta cuestión en su capítulo primero, al manifestar cómo «en los últimos años se ha venido produciendo un amplio debate en el ámbito internacional sobre la llamada responsabilidad social». De ahí que las organizaciones firmantes decidieran su inclusión para «contribuir a despejar algunas confusiones que se vienen observando alrededor de este concepto y sobre el carácter voluntario de su ejercicio». Todo ello sin olvidar su voluntad de «formular algunas aportaciones, que tendrán su continuidad en el diálogo tripartito con el Gobierno», sobre una materia en la que se reclamaba «un protagonismo más intenso de las empresas, los trabajadores y sus organizaciones representativas».

Posteriormente, se dedicaba a esta cuestión todo el capítulo VIII. En él, tras definir la RSE como «aquellos comportamientos de las organizaciones que de forma voluntaria, y adicional al cumplimiento de la legalidad, reflejan un compromiso por asumir determinados valores que existen en el ámbito social, económico o medioambiental», se señalaba la necesidad de profundizar en esta forma de gestión en el marco del dialogo social.

Finalmente, el Acuerdo Intercomfederal de Negociación Colectiva (AINC) del año $2007^{104}$ recogía en su capítulo VIII un contenido similar: resaltaba, por un lado, necesidad de un mayor grado de implicación

103 BOE № 64 del 16 marzo de 2005, disponible en <http://www.boe.es/boe/dias/2005/03/16/pdfs/ A09354-09363.pdf>.

104 BOE № 48 del 24 febrero de 2007, disponible en <http://www.juntadeandalucia.es/empleo/anexos/ estatico/1_533_0.pdf>. 
y consenso de las organizaciones firmantes con «el objetivo común de alcanzar unos mayores niveles de desarrollo económico, de calidad en el empleo, de bienestar social, de cohesión territorial y de sostenibilidad ambiental, en línea con el Libro Verde de la Comisión Europea»; y, del otro, se instaba a continuar su actividad en el marco del diálogo social que, como vimos, dio finalmente sus frutos en diciembre de 2007.

\section{III.3. La RSE y la negociación colectiva}

Ya por último tan solo quisiéramos resaltar cómo también de forma progresiva la temática sobre la responsabilidad social va incorporándose poco a poco a la negociación colectiva española. Sin detenernos aquí en un tema que desborda el escaso espacio que nos resta, nos limitaremos a señalar de qué manera el tratamiento y el contenido de estos convenios es muy dispar y se aborda desde múltiples puntos de vista ${ }^{105}$.

Sin ánimo alguno de exhaustividad, baste mencionar que en algunas ocasiones los convenios abordan esta cuestión como una de las posibles materias hacia las que se extendería la actividad de los observatorios sectoriales ${ }^{106}$, mientras que, en otros casos, se vincula expresamente a la consecución de determinadas mejoras contenidas en el convenio, en cuestiones relativas a la calidad del empleo o a la conciliación de la vida laboral y familiar ${ }^{107}$.

Un tercer grupo de convenios podría estar integrado por aquellos que, de forma más completa, aportan una auténtica definición del concepto de $\mathrm{RSE}^{108}$, a los que se unirían, en cuarto lugar, los que reconocen ciertos derechos de información a los representantes de los trabajadores sobre

105 Más ampliamente, MoLINA MARTíN, A.M. «La responsabilidad social empresarial en la negociación colectiva». En R. ESCUDERO (coordinador). La negociación colectiva en España: un enfoque interdisciplinar. Madrid: Cinca/CCOO, 2008, pp. 508 y siguientes.

106 Artículo 90 del Convenio Colectivo de Seguros, Reaseguros y Mutuas de Accidentes de Trabajo (BOE № 297 del 10 diciembre de 2008); artículo 112 del Convenio Colectivo General de Trabajo de la Industria Textil y de la Confección (BOE № 244 del 9 octubre de 2008).

107 El Preámbulo del Convenio Colectivo de las Cajas de Ahorros para los Años 2003-2006 (BOE № 64 del 15 marzo de 2004) menciona lo siguiente: «y en una manifestación, de nuevo, de responsabilidad social en el desarrollo empresarial y laboral, se establecen compromisos de creación de empleo y de estabilidad en el mismo, adecuando determinados contenidos de este convenio a fin de posibilitar el cumplimiento de los mismos». Acuerdo de la Comisión Negociadora del Convenio Colectivo del Personal Laboral de la Comunidad Autónoma de Canarias (BO Canarias № 84 del 30 de junio de 1997).

108 Así ocurre con el artículo 80 -al que se dedica todo el Capítulo XIV— del I Convenio colectivo Nacional de los Servicios de Prevención Ajenos (BOE № 220 del 11 de septiembre de 2008). De acuerdo con este precepto, la responsabilidad social de las empresas sería «esencialmente, un concepto con arreglo al cual las empresas deciden voluntariamente contribuir al logro de una sociedad mejor y un medio ambiente más limpio. Esta responsabilidad se expresa frente a los trabajadores $\mathrm{y}$, en general, frente a todos los interlocutores de la empresa, que pueden a su vez influir en su éxito. Las empresas han de dar cuenta sobre la forma en que se asumen sus responsabilidades hacia el conjunto de los individuos y grupos involucrados y/o afectados por sus actividades y decisiones a través de la participación de los trabajadores o sus representantes legales, y además, sobre el cómo participan los trabajadores, sus representantes, los consumidores y los inversores; con especial hincapié en la aplicación de buenas prácticas laborales, no colaboración con sociedades o entidades que conculquen derechos humanos y el fomento de la aplicación extensiva de la prevención de riesgos laborales». 
las memorias de sostenibilidad o sociales ${ }^{109}$, o de negociación, al exigir que los códigos de conducta se negocien previamente por los representantes de los propios trabajadores ${ }^{110}$.

Una quinta perspectiva sería la que abordaría la RSE como instrumento de control de la calidad en el empleo de las empresas subcontratadas $\mathrm{o}$, específicamente, de servicios ${ }^{111}$, sin olvidar que, en ocasiones, se encuentran expresas referencias a estas medidas de responsabilidad social en planes de viabilidad ${ }^{112}$.

Finalmente, es necesario señalar la existencia de algunos acuerdos de empresa, concretos y específicos sobre esta materia, como el Acuerdo de Responsabilidad Social Corporativa en $\mathrm{RSI}^{113}$ o recientes menciones a este por parte del acuerdo del 20 de mayo de 2008, emitido por la Mesa General de Negociación de la Administración General del Estado para ordenar en ella negociación colectiva ${ }^{114}$.

109 Véase el artículo 76 del XV Convenio Colectivo General de la Industria Química (BOE № 207 del 29 de agosto de 2007), que reconoce entre los derechos de los comités de empresa y delegados de personal conocer y tener a su disposición anualmente «el balance de aplicación y seguimiento de los compromisos asumidos por parte de las empresas que hubieran suscrito alguna fórmula de responsabilidad social -o corporativa- de empresa".

110 En este sentido, véase DA $2^{a}$ del Convenio Colectivo de la Industria del Calzado. BOE, 23 de agosto de 2007, № 202. Para comprender las razones de este temor sindical ante los códigos de conducta, véase por todos Calvo Gallego, F.J. Códigos éticos y derechos de los trabajadores. Bomarzo, 2009.

111 Artículo 16, Subcontratación de Actividades del XV Convenio Colectivo de la Industria Química (BOE № 207 del 29 de agosto de 2007): «Las empresas del sector químico velarán especialmente por la responsabilidad social de las empresas de servicios, comprobando, entre otras cuestiones, no sólo que estén al corriente de sus cotizaciones sociales y que cumplen todos los derechos y obligaciones de la relación laboral (salarios, seguridad y salud, etc.), sino también la pertenencia a su plantilla de un número importante de trabajadores fijos». En un sentido similar, puede consultarse la DT 7 del III Convenio Colectivo de Prensa Diaria (BOE № 304 del 18 de diciembre de 2008). Un contenido similar presentaba ya la DT 4 del II Convenio Colectivo Estatal del Sector de Prensa Diaria. De acuerdo con el primero de los preceptos antes mencionados, «las organizaciones firmantes recomiendan a las empresas del sector de prensa que velen especialmente por la responsabilidad social de las empresas de servicios comprobando, entre otras cuestiones, no sólo que estén al corriente de sus cotizaciones sociales y que cumplen todos los derechos y obligaciones de la relación laboral (salarios, seguridad y salud, etc.), sino también la pertenencia a su plantilla de un número importante de trabajadores fijos. Ello no excluirá la utilización por dichas empresas proveedoras de servicios del contrato de condición resolutoria o de obra y servicio vinculados a la prestación laboral propiamente dicha».

112 Véase, por ejemplo, el Acuerdo de la Comisión Paritaria del Convenio Colectivo de las Medianas Superficies de Distribución de Alimentación de la Comunidad Autónoma de Castilla y León, que aprueba el descuelgue de las tablas salariales de la empresa Pascual Hermanos S.L. (BO Castilla y León № 199 del 16 de octubre de 2009).

113 Disponible en <http://www.comfia.net/madrid/html/9249.html>.

114 BOE del 6 de junio de 2008. En él se prevé la creación de una Comisión Técnica sobre Responsabilidad Social de la AGE, que desarrollará las siguientes cuestiones: el análisis de la incidencia de la política general sobre el medio ambiente y la movilidad sostenible en el ámbito de la AGE; el análisis de la incidencia de las políticas generales relacionadas con el beneficio y el bienestar del personal en el desempeño de su trabajo en el ámbito de la AGE; el análisis de la incidencia de las políticas generales que se encuentren relacionadas con el entorno social en el que la AGE desarrolla su actividad; cualquier otro análisis que pueda estar relacionado con políticas con incidencia en la responsabilidad social de la AGE; la elaboración de un informe sobre la responsabilidad social corporativa de la AGE; y la confección de recomendaciones sobre la base de los análisis efectuados con la periodicidad que se considere oportuna.

RESPONSABILIDAD SOCIAL Y RELACIONES LABORALES EN ESPAÑA 


\section{LAS PERSPECTIVAS DE FUTURO: EL ANTEPROYECTO DE LEY DE ECONOMÍA SOSTENIBLE}

Ahora sí, para concluir, querríamos simplemente resaltar la presencia de dos menciones, ciertamente importantes, en el Anteproyecto de Ley de Economía Sostenible aprobado en el Consejo de Ministros del pasado 27 de noviembre.

El primero, que intuyo de menor importancia, se encuentra en el artículo 37 y obliga a incorporar una serie de medidas de RSE a los planes estratégicos de las sociedades mercantiles estatales y a las entidades públicas empresariales adscritas a la Administración General del Estado ${ }^{115}$.

El segundo, mucho más importante, engloba el capítulo VI y en especial el artículo 40, pues, de acuerdo con este anteproyecto, «con el objetivo de incentivar a las empresas, especialmente a las PYMES, a incorporar o desarrollar políticas de responsabilidad social, el Gobierno», pondría «a su disposición un conjunto de características e indicadores para su autoevaluación en materia de responsabilidad social, de acuerdo con los estándares internacionales en la materia». Este conjunto de características e indicadores:

[...] deberá establecerse de manera integrada, atendiendo especialmente a los objetivos de transparencia en la gestión, buen gobierno corporativo, compromiso con lo local y el medioambiente, respeto a los derechos humanos, mejora de las relaciones laborales e igualdad efectiva entre mujeres y hombres, todo ello de acuerdo con las recomendaciones que, en este sentido, haga el Consejo Estatal de la Responsabilidad Social Empresarial.

Concluye este apartado del anteproyecto señalando que las empresas que cumplan un nivel mínimo en los anteriores indicadores podrán ser acreditadas como empresas socialmente responsables por el Observatorio del Consejo Estatal de la Responsabilidad Social Empresarial.

115 En concreto, se incluyen la presentación anual de informes de gobierno corporativo, así como memorias de sostenibilidad de acuerdo con estándares comúnmente aceptados, con especial atención a la igualdad efectiva entre mujeres y hombres; la revisión de sus procesos de producción de bienes y servicios aplicando criterios de gestión medioambiental orientados al cumplimiento de las normas del sistema comunitario de gestión y auditoria medioambiental; el favorecimiento de la adopción de principios y prácticas de responsabilidad social empresarial por sus proveedores, en particular relativas a la igualdad efectiva entre mujeres y hombres; la inclusión en sus procesos de contratación, cuando la naturaleza de los contratos lo permita, de condiciones de ejecución referentes al nivel de emisión de gases de efecto invernadero y de mantenimiento o mejora de los valores medioambientales que pueden verse afectados por la ejecución del contrato. Asimismo, en los criterios de adjudicación de los contratos, cuando su objeto lo permita, se valorará el ahorro y el uso eficiente del agua y de la energía y de los materiales; el coste ambiental del ciclo de la vida, de los procedimientos y de los métodos de producción ecológicos; la generación y la gestión de residuos o el uso de materiales reciclados y reutilizados o de materiales ecológicos; $y$-sin ánimo de exhaustividad - la optimización del consumo energético de sus sedes e instalaciones mediante la celebración de contratos de servicios energéticos que permitan reducir el consumo de energía, con consecuente retribución a la empresa contratista que presente ahorros en la factura energética. 